\title{
Adipose tissue-derived stem cells differentiate into carcinoma-associated fibroblast-like cells under the influence of tumor-derived factors
}

\author{
Constantin Jotzu ${ }^{\mathrm{a}, *}$, Eckhard Alt ${ }^{\mathrm{a}, *}$, Gabriel Welte ${ }^{\mathrm{a}}, \mathrm{Jie} \mathrm{Li}^{\mathrm{b}}$, Bryan T. Hennessy ${ }^{\mathrm{b}}$, Eswaran Devarajan ${ }^{\mathrm{a}}$, \\ Srinivasalu Krishnappa ${ }^{a}$, Severin Pinilla ${ }^{a}$, Lilly Droll ${ }^{a}$ and Yao-Hua Song ${ }^{\mathrm{a}, * *}$ \\ ${ }^{a}$ Department of Molecular Pathology, University of Texas, M.D. Anderson Cancer Center, Houston, TX, USA \\ ${ }^{\mathrm{b}}$ Department of Systems Biology and Gynecologic Medical Oncology, University of Texas, M.D. Anderson Cancer \\ Center, Houston, TX, USA
}

\begin{abstract}
Carcinoma-associated fibroblasts (CAF) are considered to contribute to tumor growth, invasion and metastasis. However, the cell type of origin remains unknown. Since human adipose tissue-derived stem cells (hASCs) are locally adjacent to breast cancer cells and might directly interact with tumor cells, we investigated whether CAFs may originate from hASCs. We demonstrated that a significant percentage of hASCs differentiated into a CAF-like myofibroblastic phenotype (e.g., expression of alpha smooth muscle actin and tenascin-C) when exposed to conditioned medium from the human breast cancer lines MDAMB231 and MCF7. The conditioned medium from MDAMB231 and MCF7 contains significant amounts of transforming growth factor-beta 1 (TGF $\beta 1$ ) and the differentiation of hASCs towards CAFs is dependent on TGF $\beta 1$ signaling via Smad 3 in hASCs. The induction of CAFs can be abolished using a neutralizing antibody to TGF $\beta 1$ as well as by pretreatment of the hASCs with SB431542, a TGF $\beta 1$ receptor kinase inhibitor. Additionally, we found that these hASC-derived CAF-like cells exhibit functional properties of CAFs, including the ability to promote tumor cell invasion in an in vitro invasion assay, as well as increased expression of stromal-cell-derived factor 1 (SDF-1) and CCL5. Taken together, these data suggest that hASCs are a source of CAFs which play an important role in the tumor invasion.
\end{abstract}

Keywords: Breast cancer, mesenchymal stem cells, carcinoma-associated fibroblasts, transforming growth factor-beta 1, invasion

\section{Introduction}

Cancer invasion is influenced by tumor stroma which consists of a variety of cell types, including inflammatory cells, immune cells, fibroblasts, myofibroblasts and vascular cells [5]. Among these stromal cells the importance of cancer-associated fibroblasts (CAFs), which display traits of myofibroblasts, has been described intensively [14]. Myofibroblasts are abundant in most invasive human breast cancers and consist mostly of $\alpha$-smooth muscle actin ( $\alpha$-SMA) expressing cells [24]. It has been shown that these cells stimulate tumor growth and promote angiogenesis through secretion of stromal-cell-derived factor 1

\footnotetext{
*These authors contributed equally to this work

*** Corresponding author: Yao-Hua Song, MD, PhD, University of Texas, M.D. Anderson Cancer Center, 2SCR3.3024, Box 0951, 7435 Fannin Street, Houston, TX 77054, USA. Tel.: +1 713834 6117; Fax: +1 713834 6105; E-mail: ysong@mdanderson.org.
}

(SDF-1) [21] that binds to the chemokine receptor CXCR4 expressed by cancer cells [19]. Moreover, CAFs affect the invasive potential of cancer cells by producing proinvasive factors such as tenascin- $\mathrm{C}$ and scatter factor [6]. Translational studies of tumor stroma in both breast and colorectal cancer have demonstrated that CAFs may be a useful indicator of disease outcome or recurrence [27,31].

The origin of CAFs is not conclusively established and remains controversial [9]. It is known that fibroblasts acquire a myofibroblast-like phenotype upon exposure to TGF $\beta 1$ [23]. Recent studies have shown that at least a subset of myofibroblasts in cancer is derived from circulating bone marrow derived stem cells (BMSCs) $[7,11,17]$. However, the involvement of tissue resident stem cells in tumor stroma formation has not been investigated so far. Recent studies indicate that adipose tissue contains multipotent stem cells capable of multilineage differentiation [7,8,32]. Since these stem cells are locally adjacent to the breast tis- 
sue, we sought to elucidate whether CAF-like cells can originate from human adipose tissue-derived stem cells (hASCs) within the tumor microenvironment. In a recent study we showed that the direct interaction of hASCs with breast cancer cells stimulates cancer cell invasion through secretion of the chemokine CCL5 from tissue resident stem cells [22]. Here we demonstrate for the first time that hASCs differentiate towards CAF-like cells under the influence of cancer cell-derived TGF $\beta 1$ and that the differentiation can be abolished by inhibition of the TGF $\beta 1$ signaling pathway in hASCs. Furthermore, we found that these altered hASCs secrete elevated levels of SDF-1, CCL5 and promote the invasion of breast cancer cells in vitro.

\section{Materials and methods}

\subsection{Isolation and culture of hASCs}

Unprocessed subcutaneous adipose tissue was obtained in accordance with the Institutional Review Board from patients undergoing elective body contouring procedures as described previously [22]. Briefly, for isolation of human adipose tissue-derived stem cells (hASCs) tissue was minced and dissociated using Liberase Blendzyme 3 (F. Hoffman-La Roche Ltd.) at a concentration of 2 units/g tissue in phosphatebuffered saline (PBS; Cellegro) for $60 \mathrm{~min}$ at $37^{\circ} \mathrm{C}$ with intermittent shaking. The digested tissue was then passed through a $100 \mu \mathrm{m}$ filter (Millipore) and the floating adipocytes were separated from the stromal-vascular fraction by centrifugation at $1000 \mathrm{rpm}$ for $10 \mathrm{~min}$. The pelleted cells were washed twice with Hank's balanced salt solution (HBSS; Cellegro) and finally resuspended in alpha-modification of Eagle's medium ( $\alpha$ MEM; Cellegro) supplemented with $10 \%$ fetal bovine serum (FBS; Atlanta Biologicals), $2 \mathrm{mM}$ L-glutamine (Cellegro), $100 \mathrm{U} / \mathrm{ml}$ penicillin and $100 \mu \mathrm{g} / \mathrm{ml}$ streptomycin (Cellegro). The cells were cultured on tissue culture plates at $37^{\circ} \mathrm{C}$ in a humidified atmosphere containing $5 \% \mathrm{CO}_{2}$ and the medium was changed every 3 days. hASCs were subcultured every 4 to 5 days and cells passaged for 2-5 population doublings (PDs) were used for all experiments. All experiments were performed with hASCs isolated from three different donors and each experiment was repeated at least three times independently from each other. hASCs were positive for the mesenchymal stem cell markers CD29, CD44, CD90, CD105 and negative for CD14, CD34 and CD45 in line with previous stud- ies performed by our group for cell surface markers on hASCs [2,3]. The multi-lineage differentiation potential of these cells into adipogenic, osteogenic, neurogenic and hepatogenic lineage has been demonstrated in our laboratory [3].

\subsection{Tumor cell lines}

The human breast cancer cell lines MDAMB231 and MCF7 were purchased from the American Type Culture Collection and cultured in $\alpha$ MEM supplemented with $10 \%$ FBS, L-glutamine and penicillinstreptomycin at $37^{\circ} \mathrm{C}$ in a $5 \% \mathrm{CO}_{2}$ containing chamber.

\subsection{Flow cytometric analysis of CD surface markers on hASCs}

For flow cytometric analysis of phenotype in hASCs, cells in passage 3 were treated with $0.05 \%$ trypsin-0.53 mM EDTA, washed twice with PBS and cell aliquots $\left(10^{5}\right.$ cells $\left./ 100 \mu \mathrm{l}\right)$ were stained with primary-conjugated antibodies at room temperature for $30 \mathrm{~min}$. The conjugated antibodies used for these experiments were PE-conjugated anti-human CD14, CD29, CD34, CD90, CD105 and PerCP-conjugated anti-human CD44 and CD45. Normal mouse and rat $\mathrm{IgG}$ at the same concentrations as the primary antibodies were used as isotype-matched controls. All antibodies and matching $\mathrm{IgG}$ isotype controls were purchased from eBioscience. At least $10^{4}$ events were counted for each sample using a fluorescence-activated cell sorter (FACSCalibur, BD Biosciences) and data analysis was performed with Flow Jo software (Tree Star, Inc.).

\subsection{Exposure of hASCs to conditioned medium}

Tumor conditioned medium (TCM) was collected from $90 \%$ confluent T175 flasks $\left((8-10) \times 10^{6}\right.$ cancer cells) after $24 \mathrm{~h}$ of incubation at $37^{\circ} \mathrm{C}$ with $25 \mathrm{ml}$ of fresh, serum-free $\alpha \mathrm{MEM}$. The medium was then harvested, centrifuged at $3000 \mathrm{rpm}$ for $5 \mathrm{~min}$ at $4{ }^{\circ} \mathrm{C}$ and passed through Millipore sterile $50 \mathrm{ml}$ filtration system with $0.45 \mu \mathrm{m}$ polyvinylidene difluoride membrane. $\mathrm{CM}$ was stored at $-80^{\circ} \mathrm{C}$ in aliquots for subsequent use. hASCs were serum-starved with $0 \%$ FBS $\alpha$ MEM and subsequently exposed to conditioned medium (CM) and the CM was changed every second day for the entire culturing period ( $24 \mathrm{~h}$ to 4 days). 


\subsection{TGF $\beta$ receptor kinase inhibition and anti-TGF $\beta 1$ treatment}

For inhibition of the TGF $\beta$ type 1 receptor-like kinase, cells were preincubated with SB431542 (10 $\mu \mathrm{M}$; Sigma-Aldrich) or DMSO as a vehicle for $30 \mathrm{~min}$. To neutralize TGF $\beta 1$, cells were cultured in the presence of anti-TGF $\beta 1$ neutralizing antibody $(0.2 \mu \mathrm{g} / \mathrm{ml}$; R\&D Systems; catalog number: AF-101-NA) or the control Normal Chicken IgY (R\&D Systems; catalog number: AB-101-C).

\subsection{Immunofluorescence analysis}

For immunostaining, cells were grown to subconfluence in 6-well plates with growth medium containing $10 \%$ FBS, and then incubated with serum-free medium for $24 \mathrm{~h}$. The serum-starved cells were treated under appropriate conditions, fixed in $4 \%$ paraformaldehyde (PFA) for $10 \mathrm{~min}$ at room temperature, washed with PBS, blocked with $10 \%$ goat serum (SigmaAldrich), and then incubated with anti-alpha smooth muscle actin (1:250; Clone 1A4; Sigma-Aldrich) or anti-tenascin-C (1:250; Clone BC-24) antibodies for $1 \mathrm{~h}$ at room temperature. Following further washing the cells were incubated with Alexa Fluor 488conjugated goat anti-mouse secondary antibody (Invitrogen, Molecular Probes) for $1 \mathrm{~h}$ at a dilution of 1:500. For TGF $\beta$ type II receptors staining, the cells were stained with the fluorescein conjugated anti-TGF $\beta$ RII antibody (1:50; Clone H-567; Santa Cruz Biotechnology). Finally, all cells were counterstained with the nuclear dye Hoechst 33342 (Sigma-Aldrich) and examined with a fluorescence microscope. hASCs cultured under different conditions were quantified for the expression of alpha smooth muscle actin ( $\alpha$-SMA) and cells staining positive for $\alpha$-SMA were counted as a fraction of total cell numbers $(>70$ counted cells per view field) in nine independent fields in each group at a $10 \times$ magnification under the microscope. The experiments were repeated at least three times.

\subsection{Enzyme-linked immunosorbent assay}

ELISA was performed using the Human TGF $\beta 1$, CXCL12/SDF-1 $\alpha$ and CCL5 Quantikine Kit (R\&D Systems; catalog number: DB100B, DSA00 and DRN00B) according to the manufacturer's description and experiments were repeated at least three times. Briefly, cells were treated under appropriate conditions and cell culture supernatants were collected, cen- trifuged and filtered through a $0.45 \mu \mathrm{m}$ Steriflip Filter Unit (Millipore). The absorbance $450 \mathrm{~nm}$ for each sample was analyzed by an ELISA reader and interpolated with a standard curve.

\subsection{Western blot analysis}

Serum-starved hASCs were treated under appropriate conditions, washed with ice-cold PBS, and cells were resuspended in lysis buffer (Cell Signaling), including protease inhibitor cocktail (Roche Diagnostics). Approximately $24 \mu \mathrm{g}$ protein extract were run on pre-cast SDS PAGE gels (BioRad) for each sample and transferred to polyvinylindene difluoride (PVDF) membranes (Millipore) with a semi-dry blotting device (Bio-Rad). After blocking with $5 \%$ nonfat milk/1× TBST for $1 \mathrm{~h}$ at RT primary antibodies were diluted in $5 \%$ nonfat milk/1× TBST and membranes were incubated with antibody mixtures overnight at $4{ }^{\circ} \mathrm{C}$. Primary antibodies used were anti-phospho-Smad3 (1:1000; Epitomics), anti-Smad3 (1:1000; Abcam), anti- $\alpha$-SMA (1:400, Abcam) and anti- $\beta$-actin (1:1000; Sigma-Aldrich). Membranes were probed with corresponding HRP-conjugated secondary antibodies (1: 2000; Cell Signaling) in 5\% nonfat milk/ $1 \times$ TBST and incubated for $1 \mathrm{~h}$ at RT. Blots were developed using ECL $^{\mathrm{TM}}$ detection reagents (GE Healthcare). The experiments were repeated at least three times independently.

\subsection{DiI staining}

The hydrophobic cyanine dye DiI ( $1,1^{\prime}$-dioctadecyl$3,3,3^{\prime}, 3^{\prime}$-tetramethylindocarbocyanine perchlorate) allows fast and easy fluorescent cell labeling of cancer cells. For cell staining confluent T25 flask of MDAMB231 cells were incubated with $3 \mathrm{ml}$ of their regular culture medium containing $15 \mu$ of DiI (Invitrogen, Molecular Probes) for $1 \mathrm{~h}$. Cells were washed twice with PBS and regular medium was added for $5 \mathrm{~min}$. This procedure was repeated twice and then cells were seeded for the following experiment.

\subsection{Invasion assays}

The invasion potential of MDAMB231 cancer cells was evaluated using a Boyden chamber with filter inserts (pore size, $8 \mu \mathrm{m}$ ) coated with Matrigel in 24-well dishes (BD Biosciences). According to the manufacturer's protocol the invasion chambers were allowed to come to RT for an hour. Then PBS was added and 
the chambers were rehydrated for $2 \mathrm{~h}$ at $37^{\circ} \mathrm{C}$. DiI stained MDAMB231 $\left(35 \times 10^{3}\right.$ cells/well $)$ were seeded alone or in co-culture with hASCs $\left(70 \times 10^{3} /\right.$ well $)$ preexposed to TCM or recombinant TGF $\beta 1(0.2 \mathrm{ng} / \mathrm{ml})$ for 4 days or with normal hASCs $\left(70 \times 10^{3} /\right.$ well $)$ at a ratio of 1:2 (MDAMB231:hASCs) in $600 \mu \mathrm{l}$ of $\alpha \mathrm{MEM} 5 \%$ FBS in the upper chamber. The lower chamber contained $\alpha \mathrm{MEM} 10 \%$ FBS. For invasion assays of MDAMB231 with conditioned medium (CM), $35 \times 10^{3}$ cancer cells/well were seeded with $\mathrm{CM}$ from hASCs treated under appropriate conditions. For preparation of hASC-CM, cells were pretreated with $10 \mu \mathrm{M}$ SB431542 or DMSO as a vehicle for $30 \mathrm{~min}$ and then cultured in serum free medium, $0.2 \mathrm{ng} / \mathrm{ml} \mathrm{re-}$ combinant TGF $\beta 1$ or MDAMB231-CM over 4 days. The medium was then changed to $\alpha$ MEM $5 \%$ FBS and conditioned for $72 \mathrm{~h}$ before use. For all invasion assays the chambers were incubated for $40 \mathrm{~h}$ at $37^{\circ} \mathrm{C}$ in $5 \% \mathrm{CO}_{2}$ and non-invaded cells were removed from the top surface of the insert by scrubbing with cotton tip swabs. Invaded cells were fixed on the membrane in 5\% PFA, washed twice with PBS and counterstained with Hoechst 33342 dye as a nuclear stain. Invaded DiI/Hoechst positive cancer cells on the underside of the filters where counted in five independent view fields at $20 \times$ magnification of each insert and the experiment was repeated at least three times. Each experiment was repeated at least three times.

\subsection{FACS sorting analysis of hASC expressing tenascin-C}

For FACS sorting analysis of tenascin-C in hASCs, cells were grown to subconfluence $(60 \%)$ in T175 flasks with growth medium containing $10 \%$ FBS. $(5-7) \times 10^{5}$ cells were incubated with serum-free medium for $24 \mathrm{~h}$. The serum-starved cells were subsequently treated for $48 \mathrm{~h}$ under appropriate conditions, harvested, washed twice with PBS and cell aliquots were incubated with anti-tenascin-C antibody (5 $\mu \mathrm{g} / \mathrm{ml}$; R\&D Systems; catalog number: MAB2138) for $20 \mathrm{~min}$. Following further washing the cells were incubated with Alexa Fluor conjugated goat anti-rat IgG secondary antibody (1:200; R\&D Systems; catalog number: NL014) for 20 min, washed twice and used for FACS sorting to separate tenascin-C positive from tenascin-C negative cells. The M.D. Anderson Cancer Centre core facility was used to sort the cells using the BD FACSAria II cell sorter and FACSDiva Version 6.1.1 software. Positive and negative tenascin-C cells were then cultured separately in
$10 \%$ FBS $\alpha$ MEM over 4 days; conditioned medium was collected from approximately 5 million cells of each group and used for CCL5 ELISA.

\subsection{Statistical analysis}

All values are presented as means \pm standard deviation (SD). For statistical analysis, Student's $t$-test was performed using SPSS 16.0 software; $P<0.05$ was considered significant.

\section{Results}

\subsection{Flow cytometric analysis of phenotype in hASCs shows expression of stem cell markers}

The phenotype of hASCs in passage 3 was analysed for different antibodies typically expressed by mesenchymal stem cells (Fig. 1). Flow cytometric analysis revealed that hASCs are positive for the mesenchymal stem cell markers CD29, CD44, CD90 and CD105. The cells are negative for CD34 and CD45, which precludes contamination with hematopoietic cells.

\subsection{Tissue resident stem cells express myofibroblast markers under the influence of the tumor microenvironment}

To explore whether tissue resident stem cells could be a potential source of myofibroblast, we established a direct co-culture system in which hASCs and MDAMB231 or MCF7 breast cancer cells were co-seeded at a 2:1 ratio (Fig. $2 \mathrm{Aa}$ and $2 \mathrm{Ab}$ ) and myofibroblasts were detected by immunostaining using a specific antibody against $\alpha$-SMA. Our data showed that hASCs contain only a small number of $\alpha$-SMA positive cells and this number increased significantly after co-culture with MDAMB231 or MCF7 cells for 4 days, suggesting that hASCs differentiated into myofibroblast in this co-culture system (Fig. 2Ac-2Af). A myofibroblast phenotype (expression of $\alpha$-SMA and tenascin-C) could also be induced by incubating hASCs with both conditioned medium from MDAMB231 or MCF7 cancer cells over a period of 4 days (Fig. 2B), indicating that tumor cell-derived humoral factors are responsible for the differentiation.

The percentage of cells expressing $\alpha$-SMA was quantified at different time points and revealed that the differentiation of hASCs towards myofibroblast-like cells was time-dependent. After culturing hASCs with 

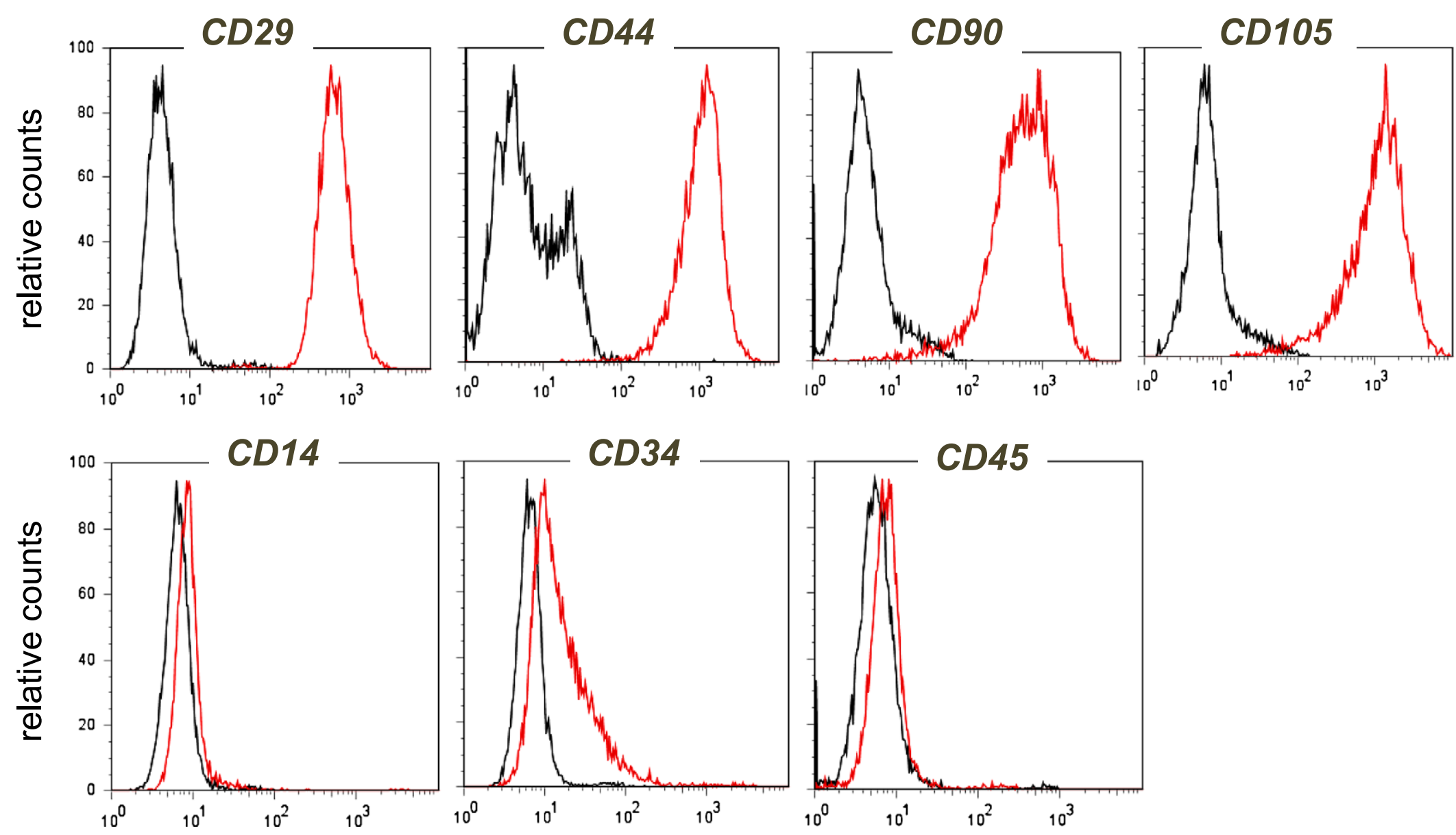

Fig. 1. hASCs express CD surface markers typical for mesenchymal stem cells. Flow cytometric analysis of CD surface markers on hASCs. Black histograms indicate isotype-matched controls; red histograms show surface antigen expression level. (The colors are visible in the online version of the article.) 


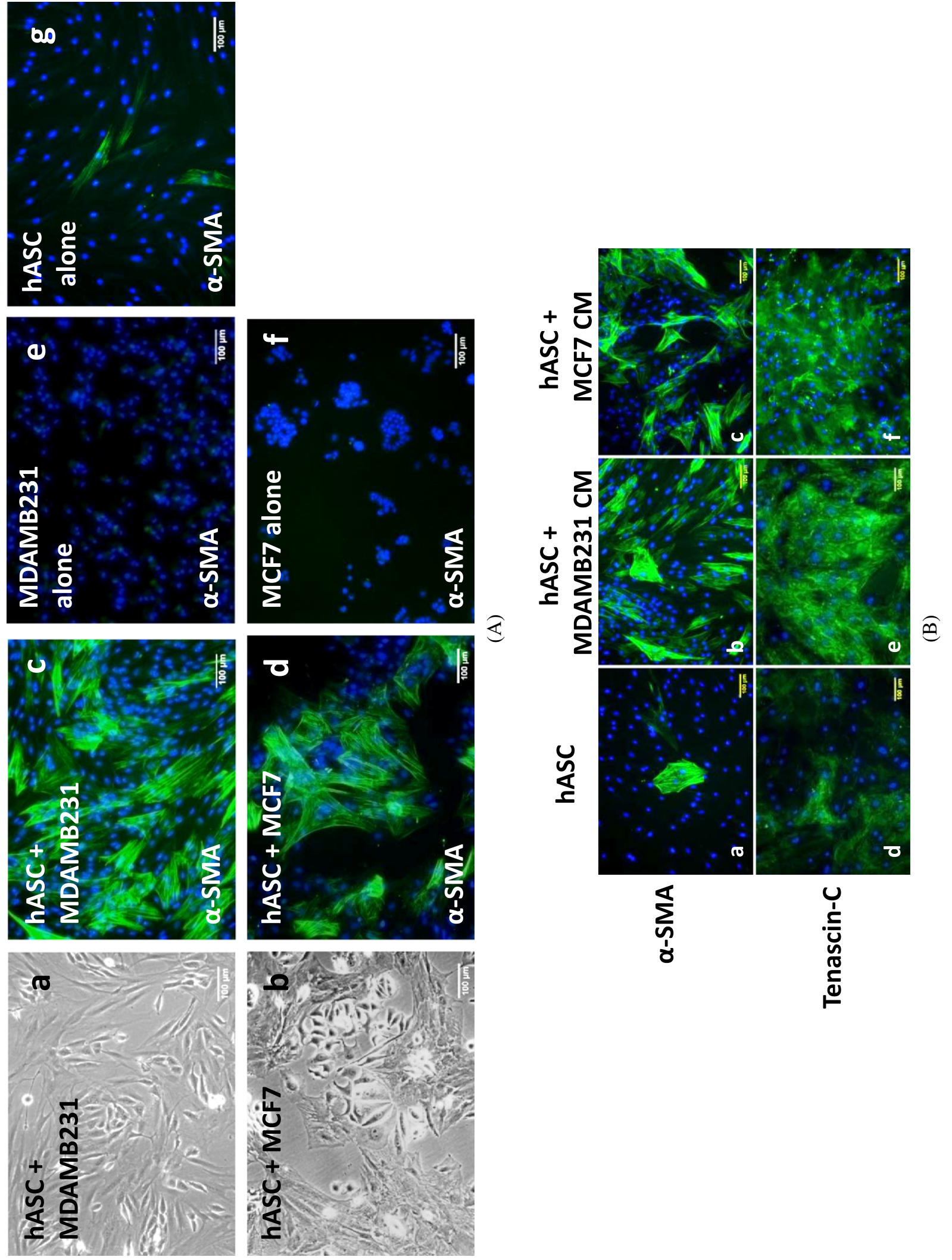




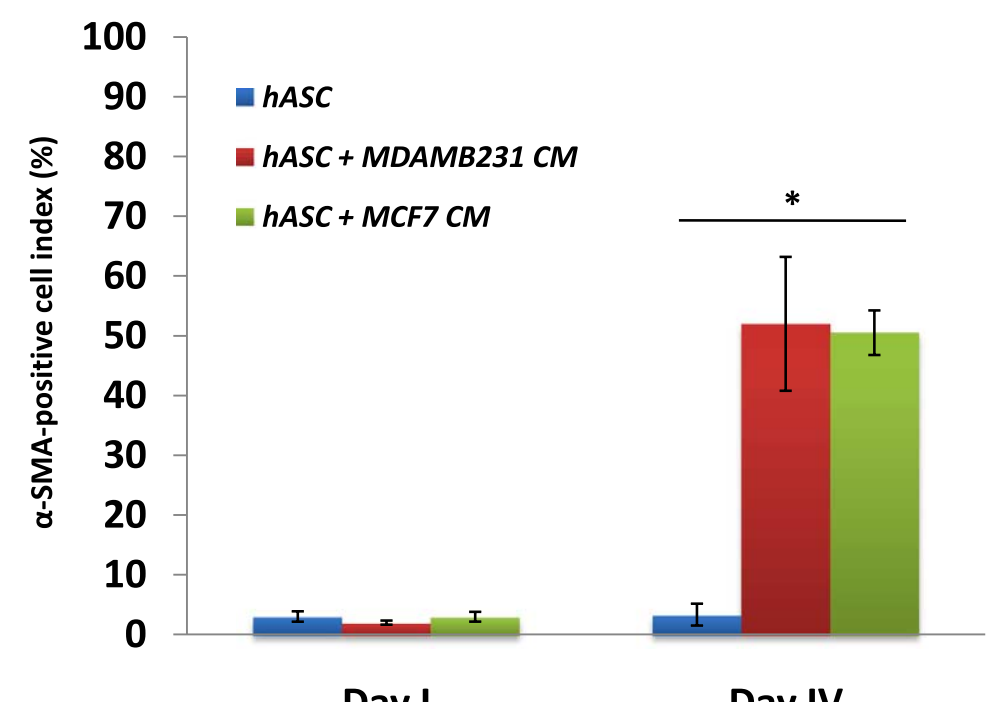

Day I

Day IV

(C)

Fig. 2. Tissue resident mesenchymal stem cells express myofibroblast markers under the influence of tumor-derived factors. (A) Brightfield picture of direct co-culture of MDAMB231 cells or MCF7 cells with hASCs grown in serum-free medium over four days (a, b). The co-culture of hASCs with MDAMB231 (c) or MCF7 (d) and monocultures of either MDAMB231 (e), MCF7 (f) or hASCs (g) were grown four days in serum-free medium and the expression of $\alpha$-SMA (green channel) was determined by immunostaining with an anti- $\alpha$-SMA antibody. Nuclei were counterstained with Hoechst 33342 and appear blue. Scale bar: $100 \mu \mathrm{m}$. (B) hASCs were cultured in serum-free medium (a, d) or with serum-free tumor conditioned medium from either MDAMB231 (b, e) or MCF7 cancer cells (c, f) for 4 days and stained with anti- $\alpha$-SMA (a-c) and anti-tenascin-C (d-f) antibodies, respectively. Scale bar: $100 \mu \mathrm{m}$. Representative pictures from at least three independent experiments are shown. (C) Quantitative analysis of the expression of $\alpha$-SMA in hASCs cultured for one to four days in either MDAMB231 or MCF7 serum-free conditioned medium or serum-free medium alone was analyzed by immunofluorescence staining (see Section 2 for details). The experiments were repeated at least three times. * $P<0.0001$ as compared to hASC alone on day IV. CM - conditioned medium; $\alpha$-SMA - alpha smooth muscle actin. (The colors are visible in the online version of the article.) 
TCM for one day, only 2\% (MDAMB231-CM) and 3\% (MCF7-CM) of the cells expressed $\alpha$-SMA, whereas $50 \%$ (MCF7-CM) and 52\% (MDAMB231-CM) of the cells expressed $\alpha$-SMA after 4 days (Fig. 2C).

\subsection{Breast cancer cell-derived TGF $\beta 1$ converts hASCs into myofibroblast-like cells}

It has been shown previously that $\alpha$-SMA expression could be induced by transforming growth factorbeta 1 (TGF $\beta 1$ ) in quiescent human breast gland fibroblasts [23]. We wondered whether MDAMB231 and MCF7 secrete TGF $\beta 1$ and whether it is involved in myofibroblast differentiation. MDAMB231 and MCF7 conditioned medium was collected at different time points for the detection of TGF $\beta 1$ by ELISA. A significant amount of TGF $\beta 1(204.9 \pm 31.9 \mathrm{pg} / \mathrm{ml}$ in CM from MDAMB231; $283.32 \pm 24.8 \mathrm{pg} / \mathrm{ml}$ in CM from MCF7) was detected in the medium after $24 \mathrm{~h}$ conditioning and TGF $\beta 1$ secretion from MDAMB231 and MCF7 reached a maximum level after $48 \mathrm{~h}$ in culture, respectively (Fig. 3A). TGF $\beta 1$ was not detected in conditioned media from hASCs cultured for 24 and $48 \mathrm{~h}$, respectively (Fig. 3A). It is known that TGF $\beta 1$ induces $\alpha$-SMA expression through binding to its type II receptor and subsequent phosphorylation and activation of Smad3 [10,16]. Immunofluorescence staining with anti-TGF $\beta$ type II receptor antibody (TGF $\beta$ RII) revealed that hASCs expressed the receptor (Fig. 3B). Furthermore, Western blot analysis demonstrated that hASCs expressed higher protein levels of $\mathrm{p}-\mathrm{Smad} 3$ and $\alpha$-SMA after exposure to CM from MDAMB231 over 4 days (Fig. 3C). Similarly, hASCs stimulated with recombinant TGF $\beta 1(0.2 \mathrm{ng} / \mathrm{ml})$ revealed strong phosphorylation of Smad3 and high protein levels of $\alpha$-SMA (Fig. 3C), which correlates with the expression of $\alpha$-SMA by immunofluorescence as shown by immunostaining (Fig. 4). More importantly, TGF $\beta$ receptor kinase inhibition with $10 \mu \mathrm{M}$ SB431542 as well as anti-TGF $\beta 1$ treatment with a neutralizing antibody markedly reduced the phosphorylation of Smad3 and protein levels of $\alpha$-SMA in hASCs (Fig. 3D). To further confirm the role of TGF $\beta 1$ in myofibroblast differentiation, we treated hASCs with different concentrations of TGF $\beta 1$ and quantitatively analyzed $\alpha$-SMA expression. We found, that exogenously added TGF $\beta 1$ dose-dependently increased the expression of $\alpha$-SMA in hASCs (Fig. 4). Furthermore, we showed that treatment with $0.2 \mathrm{ng} / \mathrm{ml}$ recombinant TGF $\beta 1$ over 4 days, which is exactly the amount of TGF $\beta 1$ secreted by MDAMB231 cells after $24 \mathrm{~h}$, elicited a stem cell re- sponse indistinguishable from that obtained with TCM ( $0 \%$ FBS; $24 \mathrm{~h}$ conditioning time) (Fig. 4). Additionally, we found that abrogation of TGF $\beta 1$-dependant activity was achieved using a neutralizing antibody against TGF $\beta 1$ in both hASCs cultured with TGF $\beta 1$ or cultured in MDAMB231-CM (Fig. 4). Furthermore, the percentage of TCM-induced expression of $\alpha$-SMA (both by MDAMB231-CM as well as MCF7-CM) was markedly reduced by pretreatment of hASCs with the TGF $\beta 1$ receptor kinase inhibitor SB431542 (Fig. 4). Hence, these results clearly indicate the involvement of cancer cell-derived TGF $\beta 1$ in the differentiation of hASCs to myofibroblast like cells.

\subsection{Secretion of SDF-1 $\alpha$ from hASCs increases upon stimulation with tumor conditioned medium}

In breast cancer a key feature of tumor activated myofibroblasts is their potential to stimulate tumor growth and to promote angiogenesis partially through their ability to secrete SDF-1 [21]. We therefore examined whether MDAMB231- or MCF7-CM could induce SDF- $1 \alpha$ protein production in hASCs. The secretion of SDF- $1 \alpha$ from TCM-activated hASCs was timedependent reaching a maximum level after $72 \mathrm{~h}$ in culture (Fig. 5A and Suppl. Fig. 1: http://www.qub.ac.uk/ isco/JCO). As shown in Fig. 5B, the increase in SDF-1 $\alpha$ protein-level after $72 \mathrm{~h}$ was 5.2 fold for hASCs cultured in MDAMB231-CM compared to the control group of hASCs cultured in regular medium $(P<0.001)$. Additionally, we assessed the involvement of TGF $\beta 1$ in the production of SDF- $1 \alpha$. As shown in Fig. 5B, the increased expression of SDF- $1 \alpha$ in TCM-activated hASCs was significantly reduced by pretreatment with SB431542 $(P<0.01)$. Interestingly, we found that $72 \mathrm{~h}$ stimulation with recombinant TGF $\beta 1$ did not affect the secretion of SDF- $1 \alpha$ from hASCs (Fig. 5B), suggesting that TGF $\beta 1$ alone is not sufficient for the TCM-induced production of SDF- $1 \alpha$, although the TGF $\beta 1$ signaling pathway may be involved in SDF-1 production.

\section{5. hASC-derived myofibroblasts promote cancer cell invasion}

An important feature of myofibroblasts is their ability to promote cancer cell invasion [6]. We established an in vitro invasion assay in order to assess the impact of hASC-derived myofibroblast on the invasion of MDMB231 cells. On the surface of a matrigel coated insert we seeded either DiI stained can- 


\section{TGF $\beta 1$ secretion}

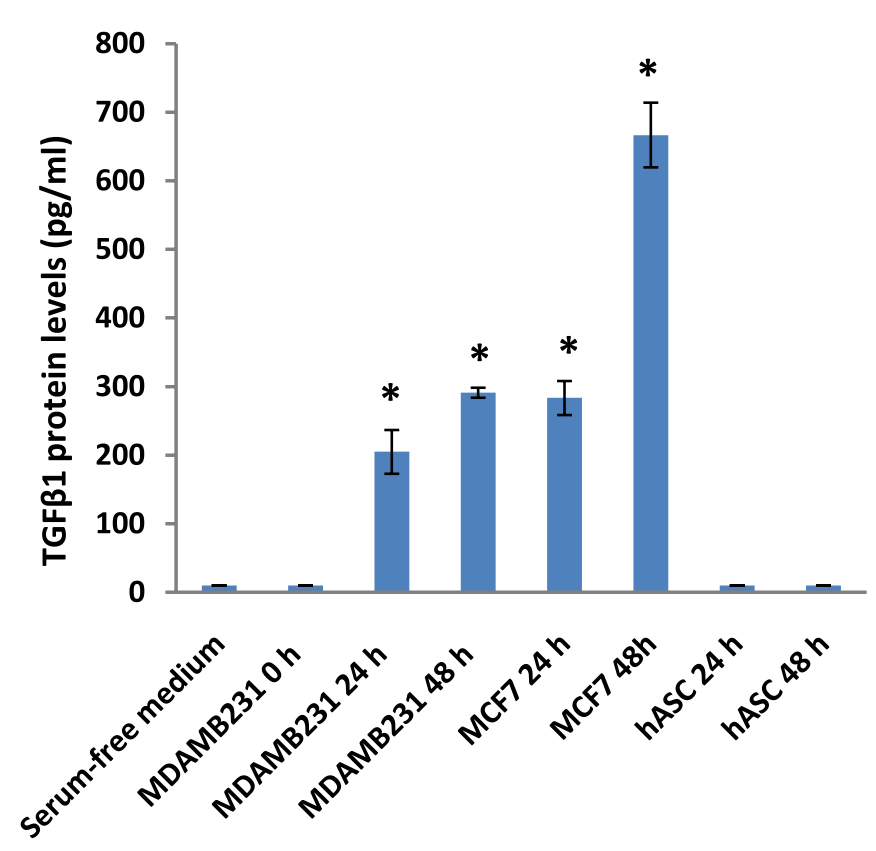

(A)

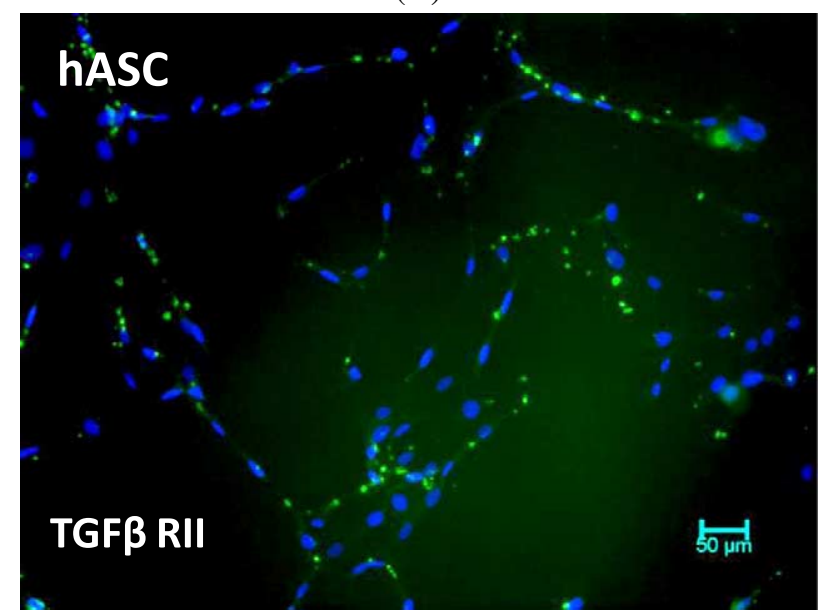

(B)

Fig. 3. Breast cancer cell-derived TGF $\beta 1$ induces the phosphorylation of Smad3 in hASCs. (A) The amounts of TGF $\beta 1$ in regular serum-free medium or serum-free conditioned medium from MDAMB231, MCF7 and hASCs measured by ELISA at different time points. Data represent mean $\pm \mathrm{SD}(n=3) .{ }^{*} P<0.0001$ as compared to serum-free medium. (B) Immunofluorescence staining of hASCs with a fluorescein conjugated anti-TGF $\beta$ type II receptor antibody (green channel). Nuclei were counterstained with Hoechst and appear blue in the photograph. Scale bar: $50 \mu \mathrm{m}$. A representative picture from at least three independent experiments is shown. (C) hASCs were exposed to either serum-free medium alone, MDAMB231-CM (0\% FBS; $24 \mathrm{~h}$ conditioning time), or $0.2 \mathrm{ng} / \mathrm{ml}$ recombinant TGF $\beta 1$ over 4 days. The expression levels of Smad3, phoshorylated Smad3, $\alpha$-SMA and $\beta$-actin were determined by Western blot analysis using anti-Smad3, anti-p-Smad3, anti- $\alpha$-SMA and anti- $\beta$-actin antibodies, respectively. $\beta$-actin was used as a loading control. Representative data from three independent experiments are shown. (D) hASC were pretreated with vehicles or $10 \mu \mathrm{M} \mathrm{SB} 431542$ (TGF $\beta 1$ activin receptor-like kinases inhibitor) for 30 min and then exposed to serum-free medium (control) or MDAMB231-CM for 4 days. To neutralize TGF $\beta 1$, cells were cultured in TCM for 4 days in the presence of anti-TGF $\beta 1$ neutralizing-antibody $(0.2 \mu \mathrm{g} / \mathrm{ml})$. The expression levels of Smad3, phoshorylated Smad3, $\alpha$-SMA and $\beta$-actin were determined by Western blot analysis. For all Western blot experiments representative data from three independent experiments are shown. CM - conditioned medium; TGF $\beta$ RII - transforming growth factor beta type II receptor; p-Smad3 - phosphorylated Smad3. (The colors are visible in the online version of the article.) 


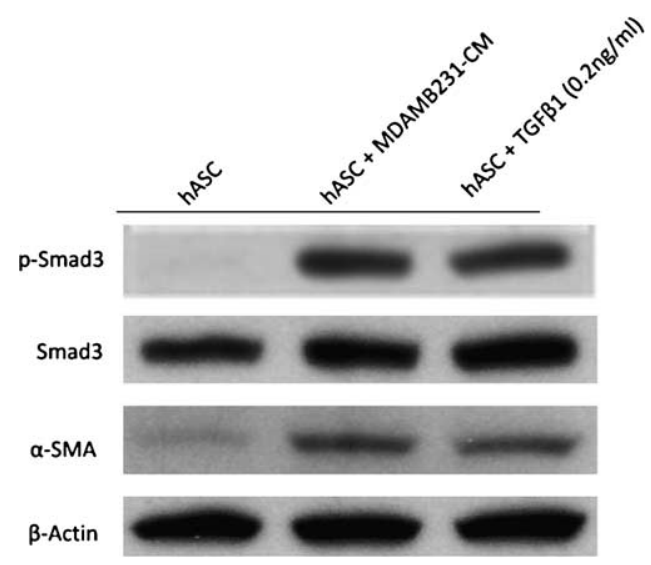

(C)

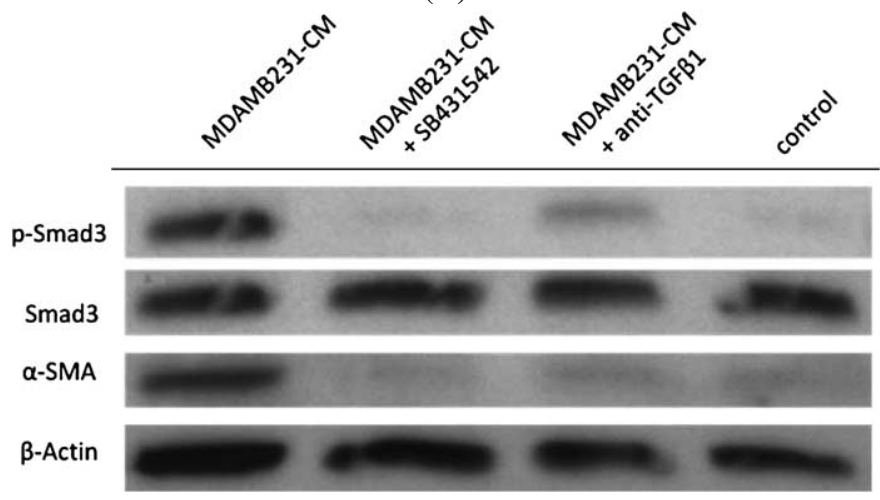

(D)

Fig. 3. (Continued.)

cer cells alone or in co-culture with hASC previously grown in regular medium, tumor conditioned medium or in regular medium containing $0.2 \mathrm{ng} / \mathrm{ml} \mathrm{TGF} \beta 1$, respectively. When counting the cancer cells that invaded into the matrigel after $40 \mathrm{~h}$, we found that significantly more cancer cells $(96.9 \pm 23.2$ cells/view field) invaded the coated membrane when co-seeded with hASCs as compared to the mono-culture control group (33.6 \pm 14.9 cells/view field, Fig. 6). Furthermore, we found that MDAMB231 cells become more invasive when co-cultured with hASCs that have been pre-incubated with either TCM or TGF $\beta 1$ for 4 days (Fig. 6). To assess the influence of conditioned medium from "CAF-like" cells on the invasion of breast cancer cells, we performed another series of invasion assays with MDAMB231 cells. For this assay the cancer cells were seeded alone on the surface of the coated inserts and exposed to conditioned medium ( $72 \mathrm{~h}$ conditioning time; $5 \%$ FBS) from hASCs, TGF $\beta 1$-treated hASCs, TCM-activated hASCs and TCM-activated hASCs previously incubated with $10 \mu \mathrm{M}$ SB431542.
After $40 \mathrm{~h}$ the cells were stained with the nuclear dye Hoechst 33342 and the invaded cells were counted in five independent view fields (representative pictures of invaded cells are shown in Fig. 7Aa-7Ae). As shown in Fig. 7B, the invasion assay revealed that both $\mathrm{CM}$ from "CAF-like" cells as well as CM from TGF $\beta 1$ treated hASCs significantly increased the invasion of MDAMB231 cancer cells $(P<0.005$ as compared to $\mathrm{CM}$ from hASCs). Moreover, the invasive capacity of cancer cells grown in CM from "CAF-like" cells pretreated with the tyrosine kinase inhibitor SB431542 was significantly reduced when compared to the invasive rate of cancer cells grown in CM from "CAF-like" cells for the same time $(P<0.0001)$.

\subsection{CCL5 secretion is elevated in hASC-derived myofibroblasts}

We previously have shown that hASC-derived CCL5 promotes breast cancer cell invasion in vitro [22]. In order to assess the role of CCL5 in our current 


\section{aSMA induction by TGFß1}

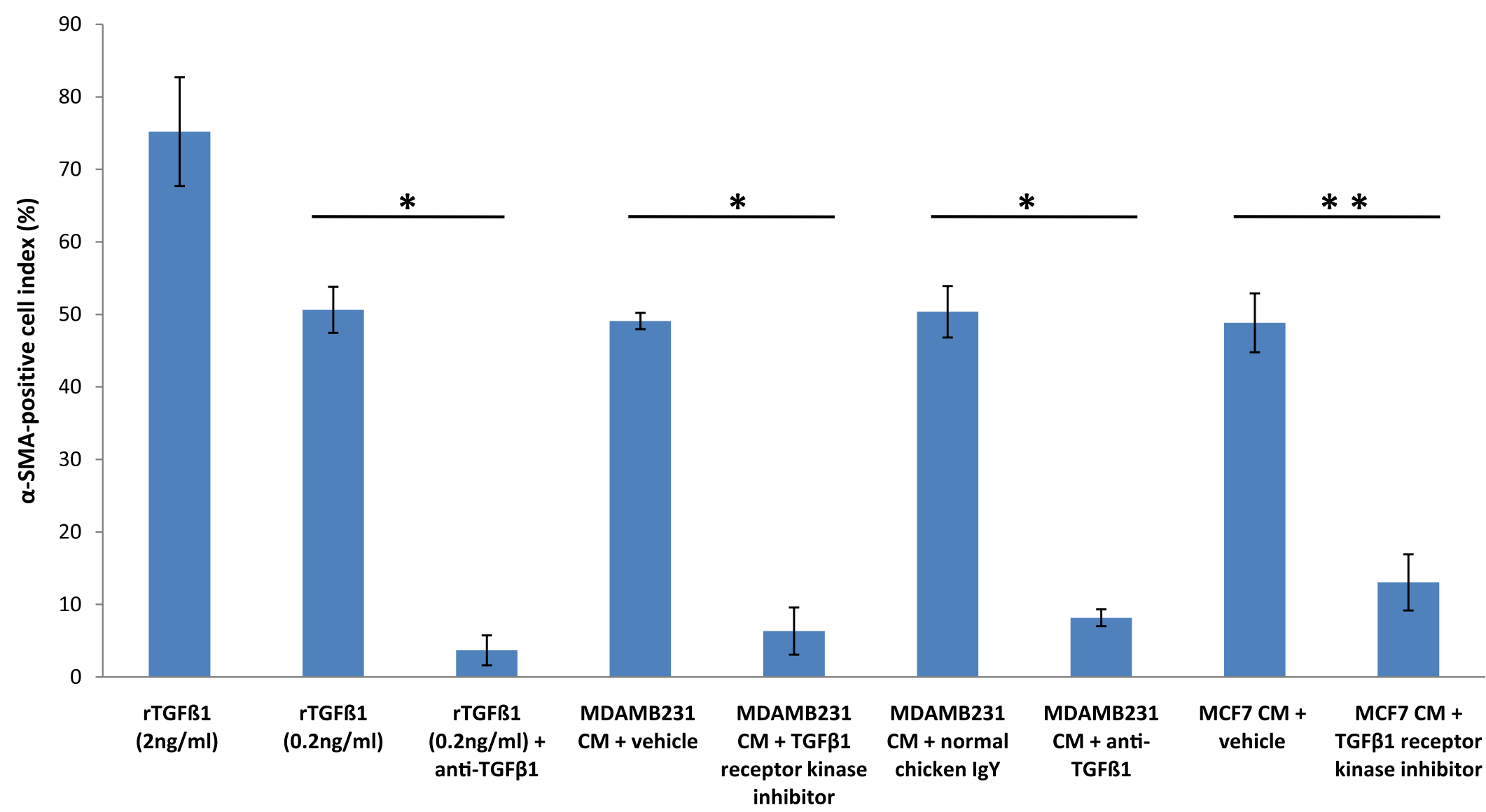

\section{hASC culturing conditions}

Fig. 4. TGF $\beta 1$ is critical to hASC differentiation towards myofibroblast-like cells. Serum-starved hASCs were treated with different concentrations of recombinant TGF $\beta 1$ ( 0.2 and 2 ng/ml) or cultured in MDAMB231 conditioned medium ( $0 \%$ FBS; $24 \mathrm{~h}$ conditioning time) for 4 days in the presence of anti-TGF $\beta 1$ neutralizing antibody $(0.2 \mu \mathrm{g} / \mathrm{ml})$ or control normal chicken $\mathrm{IgY}(0.2 \mu \mathrm{g} / \mathrm{ml})$. For inhibition of TGF $\beta 1$ activin receptor-like kinases hASCs were pretreated with vehicles (DMSO) or $10 \mu \mathrm{M}$ SB431542 for 30 min and then exposed to CM from either MDAMB231 or MCF7 cancer cells for 4 days. The quantitative expression of $\alpha$-SMA in hASCs was analyzed by immunofluorescence staining and cells positive for $\alpha$-SMA where counted as a fraction of total cell numbers in each group. Data represent average value $\pm \operatorname{SD}(n=3) .{ }^{*} P<0.0001,{ }^{* *} P<0.0004$. CM - conditioned medium; $\alpha$-SMA - alpha smooth muscle actin; rTGF $\beta 1$ - recombinant transforming growth factor beta 1. (The colors are visible in the online version of the article.) 


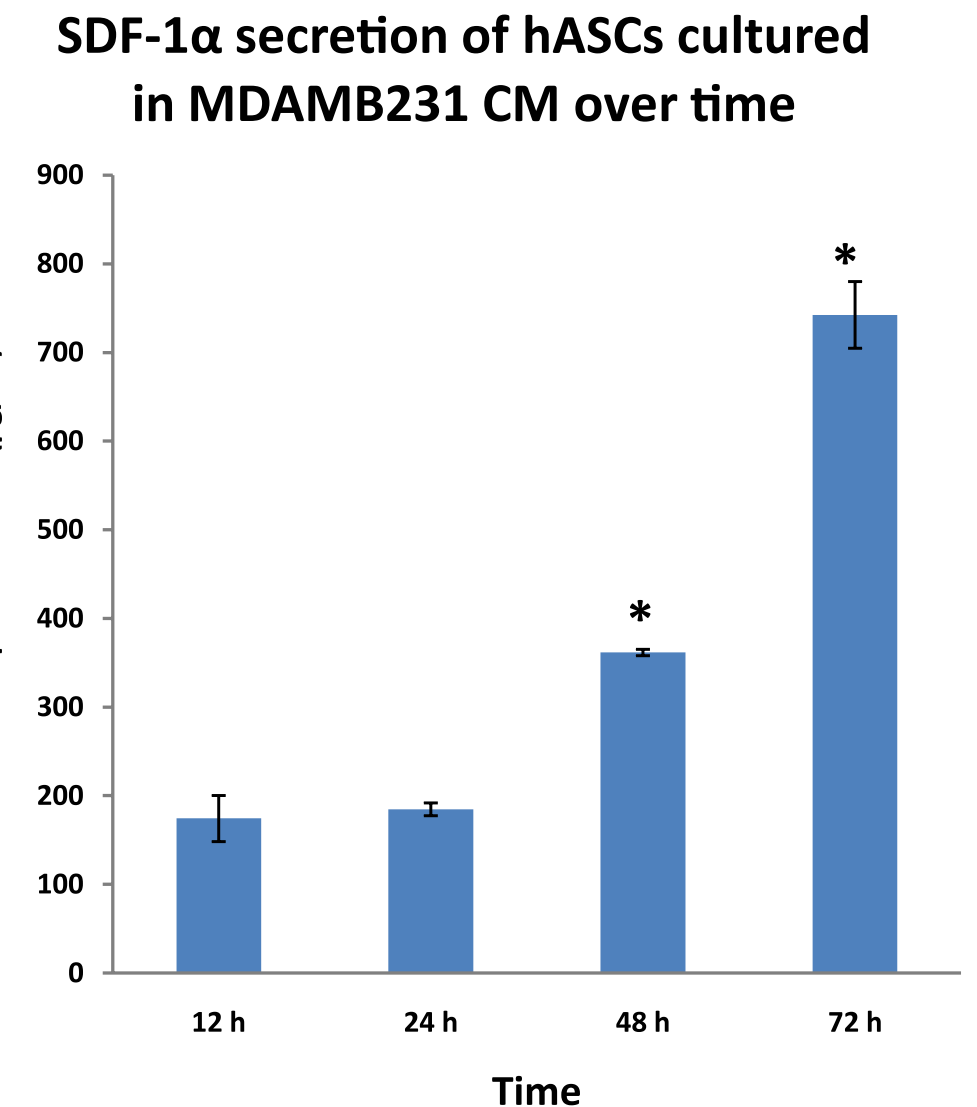

(A)

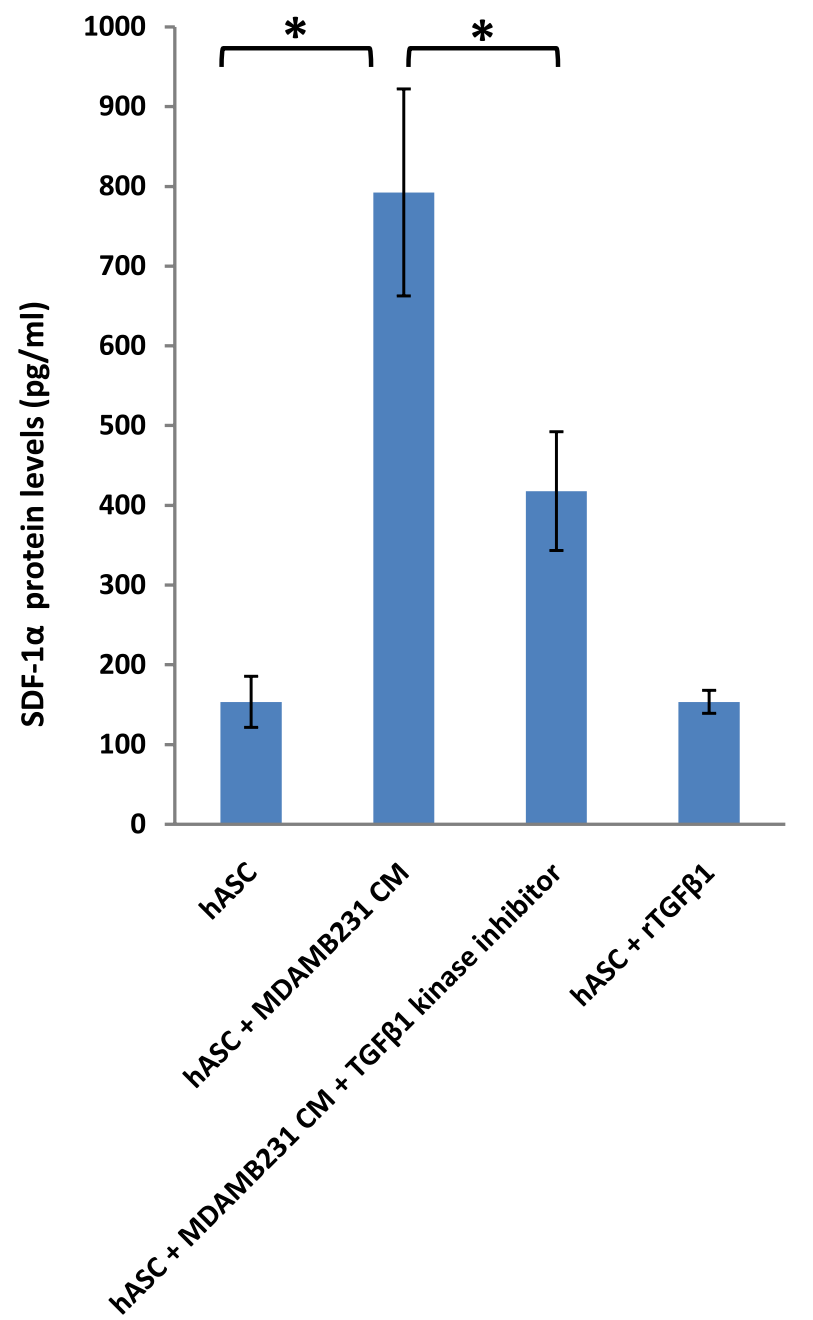

(B)

Fig. 5. Tumor conditioned medium stimulates the secretion of SDF-1 $\alpha$ from hASCs. (A) Protein levels of SDF-1 $\alpha$ secreted from hASCs exposed to MDAMB231 conditioned medium over time (12-72 h) was measured by ELISA. The experiment was repeated three times. * $P<0.0001$ versus $12 \mathrm{~h}$ MDAMB231-CM. (B) Serum-starved hASCs were pretreated with vehicles, or $10 \mu \mathrm{M}$ SB431542 (TGF $\beta 1$ receptor kinase inhibitor) and then cultured in serum-free regular medium, MDAMB231 conditioned medium or exposed to $0.2 \mathrm{ng} / \mathrm{ml} \mathrm{rTGF} \beta 1 \mathrm{for} 72 \mathrm{~h}$. Cell culture supernatants were subjected to ELISA for the measurement of SDF- $1 \alpha$ levels. Data represent mean $\pm \operatorname{SD}(n=3) .{ }^{*} P<0.001,{ }^{* *} P<0.01$. SDF-1 $\alpha$ - stromal-cell-derived factor 1 alpha; rTGF $\beta 1$ - recombinant transforming growth factor beta 1. (The colors are visible in the online version of the article.) 

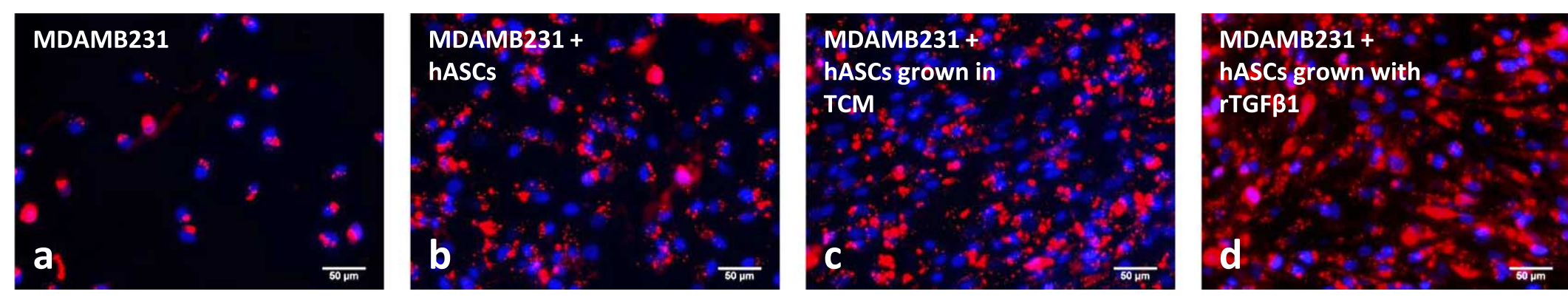

(A)

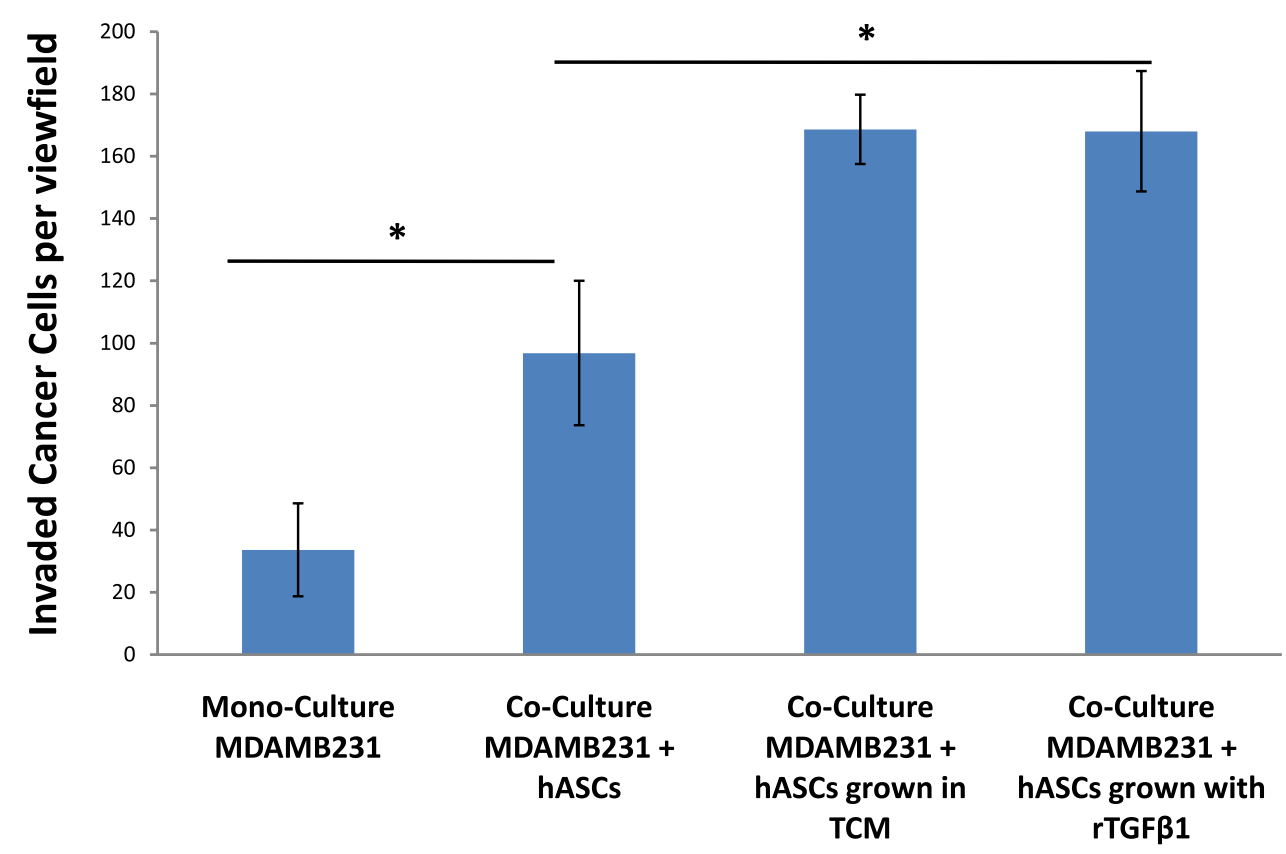

(B)

Fig. 6. Tumor conditioned medium activated hASCs and recombinant TGF $\beta 1$-treated hASCs promote tumor cell invasion. (A) Fluorescent images of DiI stained MDAMB231 cancer cells (red channel) that invaded into matrigel after $40 \mathrm{~h}$. The nuclei were counterstained with Hoechst (blue). Overlay of red with blue signal shows invaded cancer cells when (a) seeded alone or co-cultured with hASCs previously grown in (b) regular medium, (c) MDAMB231 tumor conditioned medium (TCM) or with (d) $0.2 \mathrm{ng} / \mathrm{ml}$ recombinant TGF $\beta 1$ for 4 days. Representative pictures of three independent experiments are shown. Scale bar: $50 \mu \mathrm{m}$. (B) Invaded DiI/Hoechst-positive MDAMB231 cancer cells were counted in five independent view fields in each group and are shown as mean \pm SD with experiments being repeated at least three times. ${ }^{*} P<0.001$. TCM - tumor conditioned medium; rTGF $\beta 1$ - recombinant transforming growth factor beta 1 . (The colors are visible in the online version of the article.) 

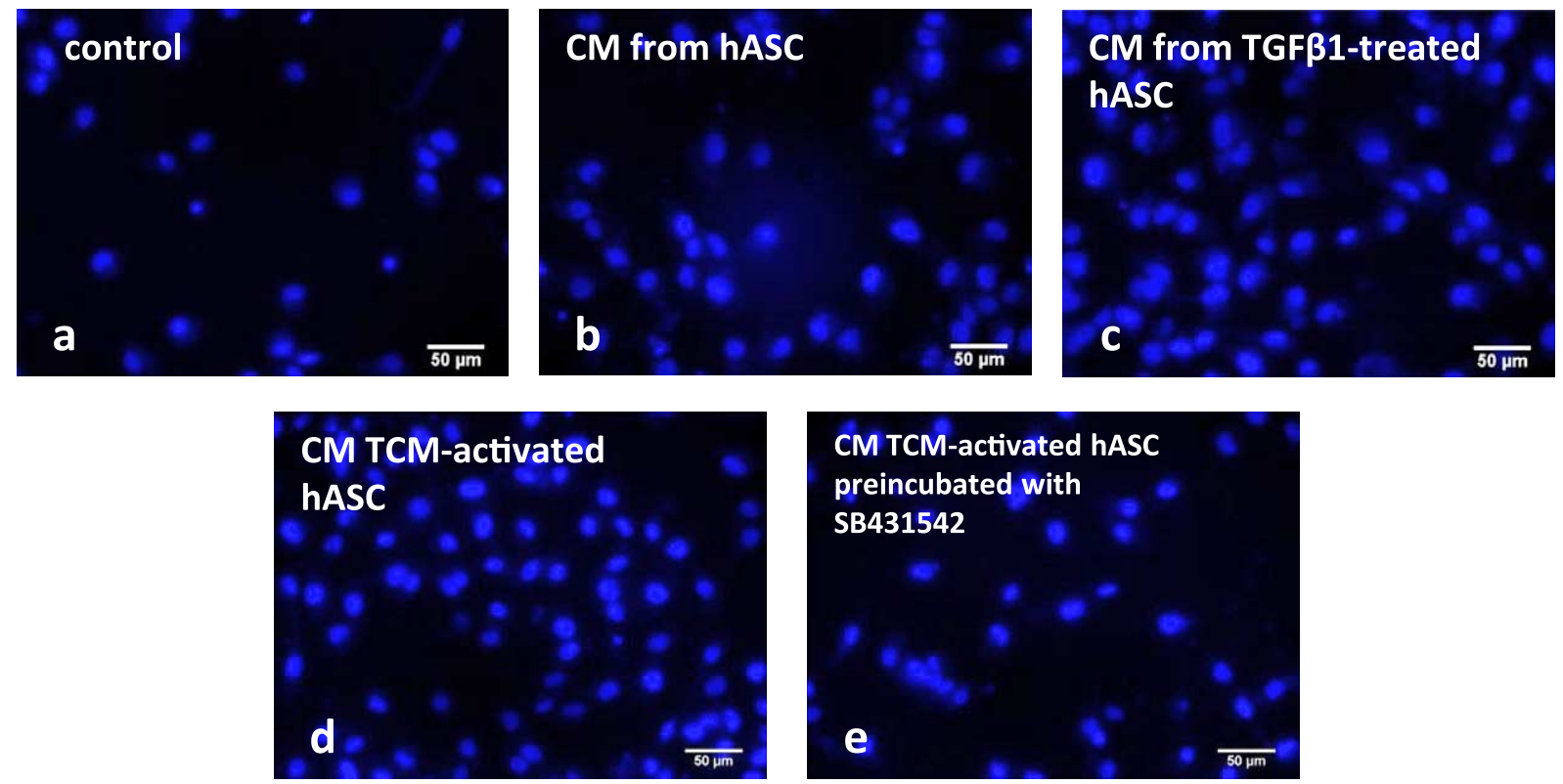

(A)

Fig. 7. Conditioned medium from both rTGF $\beta 1$-treated hASCs and CAF-like hASCs promotes tumor cell invasion. (A) Fluorescent images of MDAMB231 cancer cells that invaded into matrigel after $40 \mathrm{~h}$. The nuclei of the invaded cells were stained with the nuclear dye Hoechst 33342 and appear blue. Images show invaded cancer cells when cultured in (a) regular medium containing 5\% FBS, (b) CM from hASCs, (c) CM from rTGF $\beta$ 1-treated hASCs, (d) CM from "CAF-like" hASCs and (e) CM from "CAF-like" hASCs pretreated for 30 min with $10 \mu$ M SB431542 (tyrosine kinase inhibitor). Representative pictures of three independent experiments are shown. Scale bar: $50 \mu \mathrm{m}$. (B) Hoechst-positive MDAMB231 cancer cells were counted in five independent view fields in each group and are shown as mean \pm SD. Experiments were repeated at least three times. ${ }^{*} P<0.001 ;{ }^{* *} P<0.005 ;{ }^{* * *} P<0.0001$. CM - conditioned medium; rTGF $\beta 1$ - recombinant transforming growth factor beta 1 . (The colors are visible in the online version of the article.)

study, we performed additional experiments and explored whether hASC-derived CAFs are a source of CCL5. hASCs were cultured in either MDAMB231$\mathrm{CM}(0 \% \mathrm{FBS} ; 24 \mathrm{~h}$ conditioning time) or serum-free regular growth medium over 4 days and subsequently separated by cell sorting using anti-tenascin-C antibody. FACS sorting analysis revealed that after 4 days in tumor conditioned medium $24.8 \%$ of the cells expressed tenascin-C whereas only $0.4 \%$ of the cells cultured in serum-free regular medium expressed this myofibroblast marker (Fig. 8Ab and 8Ac). The separated cell fractions of tenascin- $\mathrm{C}$ positive and negative cells were subsequently cultured in regular growth medium over 4 days and conditioned medium from these cells was used for CCL5 ELISA experiments. We found that cells positive for tenascin-C produced significantly more CCL5 than the tenascin-C negative cell fraction (744.13 \pm 67.95 as compared to $217.38 \pm$ 21.95 pg/500,000 cells; Fig. 8B). Together these data confirm that hASCs contain a subpopulation of cells that are tenascin- $\mathrm{C}$ positive and these cells are the main source of CCL5.

\section{Discussion}

Bone marrow derived mesenchymal stem cells have recently been found to integrate into the tumor associated stroma and differentiated into myofibroblasts which act in a paracrine fashion on the cancer cells to enhance their invasion [25]. However, the potential of adjacent tissue resident stem cells to differentiate into myofibroblasts and support breast cancer cell invasion has not yet been investigated. In this study we showed for the first time that hASCs exhibit increased expression of myofibroblast markers tenascin-C and $\alpha$-SMA when exposed to tumor cell conditioned medium from two different breast cancer cell lines MDAMB231 and MCF7. Additionally, hASCs secrete increased protein levels of SDF-1 when cultured in tumor cell conditioned medium and these TCM-activated hASCs promote the invasion of cancer cells in vitro. We further showed that tumor conditioned medium from MDAMB231 and MCF7 cells contains significant amounts of $\mathrm{TGF} \beta 1$ and that the differentiation of hASCs towards CAFs is dependent on TGF $\beta 1$ signaling via Smad3 in hASCs. 


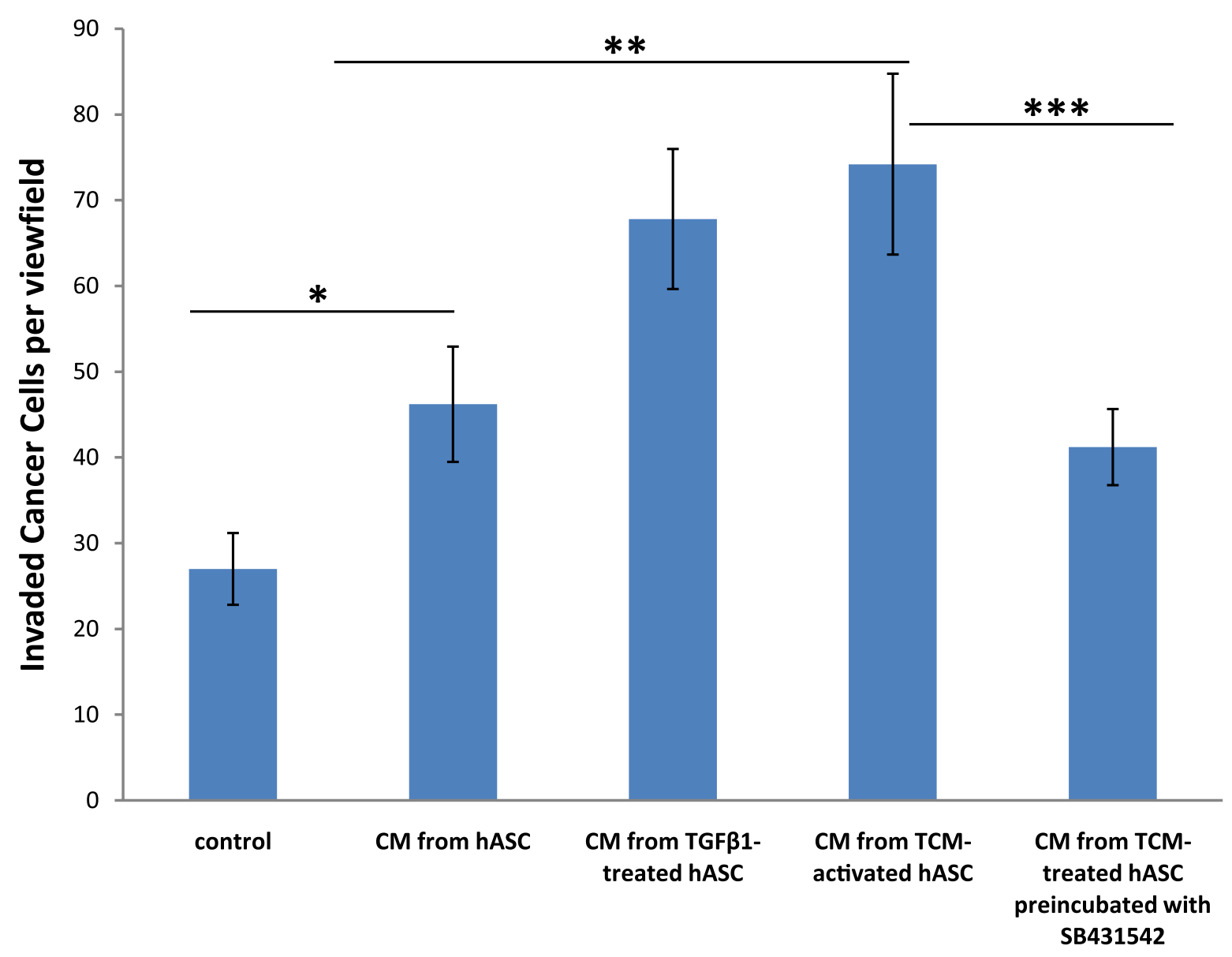

(B)

Fig. 7. (Continued.)

TGF- $\beta 1$ is considered to have a central role in inducing the myofibroblastic phenotype, because it is capable of up-regulating fibroblast $\alpha$-SMA and collagen both in vitro and in vivo [28]. In many types of cancers, TGF- $\beta 1$ is overexpressed by carcinoma cells [26], and it has been proposed previously that the expression of this cytokine by prostate carcinoma cells induces reactive stroma [30].

Moreover, mesenchymal stem cells undergo myofibroblast differentiation, including increased production of $\alpha$-SMA in response to TGF- $\beta$ [29]. Our findings that addition of either a TGF $\beta 1$ neutralizing antibody or pretreatment with a $\mathrm{TGF} \beta$ receptor kinase inhibitor completely blocked the phenotypic switch of hASCs towards $\alpha$-SMA expressing phenotype are consistent with these previous reports.

The CXCR4/SDF-1 axis plays a crucial role in the targeting of metastatic cancer cells of various origins (e.g., breast, kidney, lung, pancreas and prostate), as well as leukemic cells, to the bone marrow, lymph nodes and lung; this is achieved by promoting the migration of the malignant cells towards SDF-1 produced by the stroma of these target organs [4]. We have shown previously that the SDF-1/CXCR4 axis plays an important role in mediating ASC's tumorpromoting effect [18]. Orimo et al. [21] showed that the $\alpha$-SMA protein present on myofibroblasts in tumor stroma was largely co-localized with the SDF-1 protein. In contrast, they failed to detect any fibroblast-like cells positive for SDF-1 in non-cancer stroma. These findings are in line with our data that hASCs exposed to tumor conditioned media produced more SDF-1. These findings suggest that tumor cells produce specific factors that induce the production of SDF-1 by myofibroblasts. In an attempt to define the specific factor, we asked whether $\operatorname{TGF} \beta 1$ could be a potential candidate since our data indicate that TGF $\beta 1$ treatment resulted in increased percentage of $\alpha$-SMA pos- 

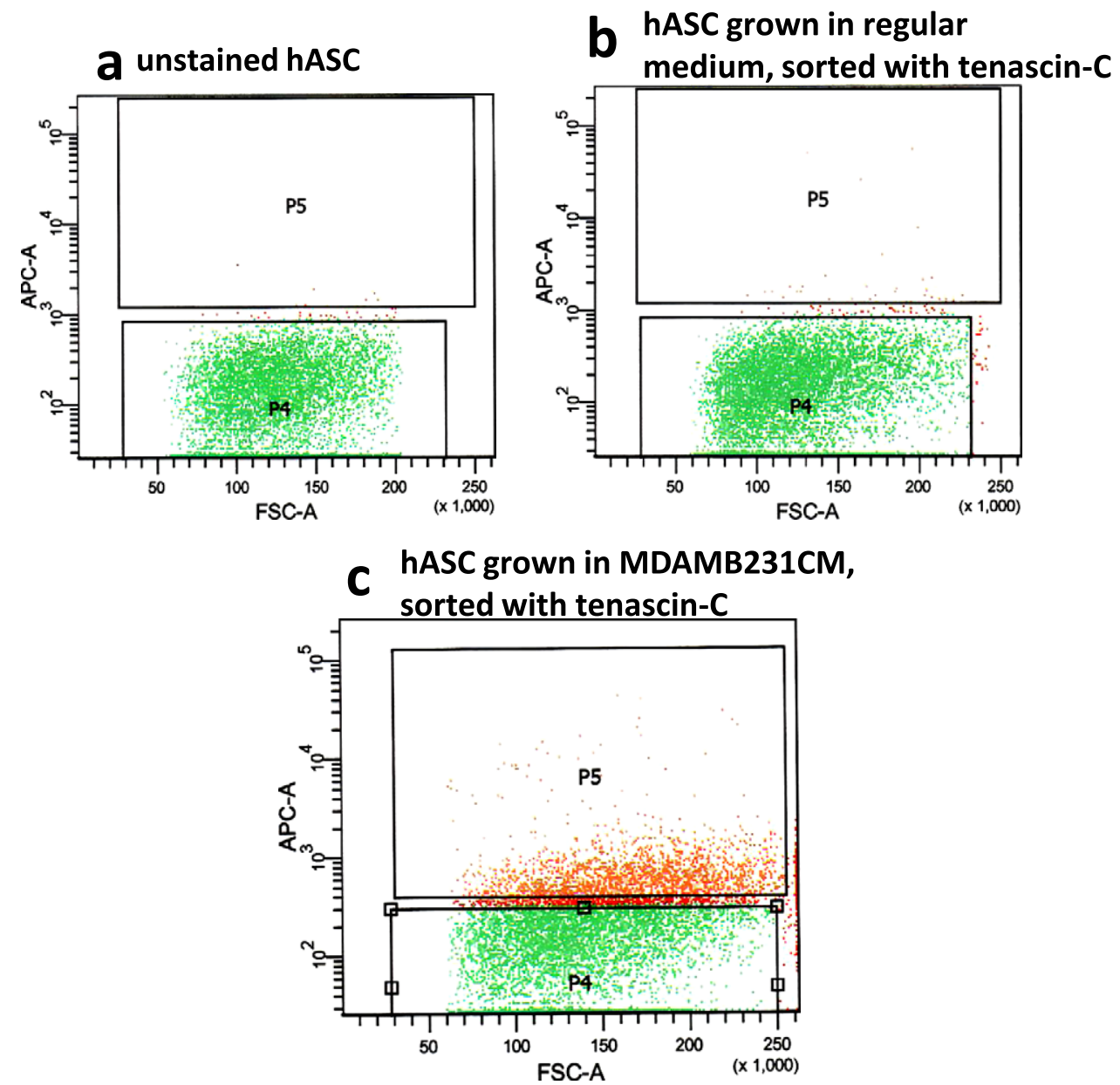

(A)

Fig. 8. Tenascin-C positive myofibroblasts produce elevated levels of CCL5. (A) FACS sorting analysis of hASCs for tenascin-C expression. Serum-starved hASCs were cultured in MDAMB231 conditioned medium (0\% FBS; $24 \mathrm{~h}$ conditioning time) or serum-free regular growth medium over 4 days and subsequently sorted with FACS cell sorter using anti-tenascin-C antibody ( $5 \mu \mathrm{g} / \mathrm{ml})$. Green dots in population P4 indicate tenascin-C negative cell counts; red dots in population P5 indicate tenascin-C positive cell counts. Representative images show cell counts from (b) FACS sorting of hASCs cultured in serum-free regular growth medium over 4 days $(0.4 \%$ positive tenascin-C cells) and (c) hASCs grown in MDAMB231-CM over 4 days (24.8\% positive tenascin-C cells). Unstained hASCs were used as negative control for sorting (a). (B) Cell fractions of tenascin-C positive and negative cells as sorted by FACS were cultured in regular growth medium over 4 days and conditioned medium from these cells was used for detection of CCL5 protein levels by ELISA. Data represent mean $\pm \mathrm{SD}(n=3)$. ${ }^{*} P<0.0003$. P4 - tenascin-C negative cell population; $\mathrm{P} 5$ - tenascin-C positive population; $\mathrm{CM}$ - conditioned medium. (The colors are visible in the online version of the article.)

itive cells within the hASCs. Our data showed that although pharmacological inhibition of TGF $\beta 1$ receptor significantly reduces the secretion of SDF-1 in TCMactivated hASCs, direct stimulation of hASCs with TGF $\beta 1$ does not change the protein level of SDF-1. These data suggest that the TGF signaling pathway may be involved but might not be sufficient by itself to induce SDF-1 production.

Another key feature of cancer associated myofibroblasts is their ability to promote the invasion of cancer cells [5]. We demonstrated that hASCs pro- mote cancer cell invasion in co-culture. We further showed that the invasion promoting effect is more pronounced in hASCs that have been cultured either with tumor cell conditioned medium or recombinant $\operatorname{TGF} \beta 1$. These data indicate that myofibroblasts are responsible for the enhanced invasion. We have shown previously that hASC-derived CCL5 is responsible for enhanced tumor cell invasion [22]. We conducted further experiments to find out the cellular sources of CCL5. Our results showed that CCL5 is mainly produced by tenascin-C positive cells. Hence these data 


\section{CCL5 secretion}

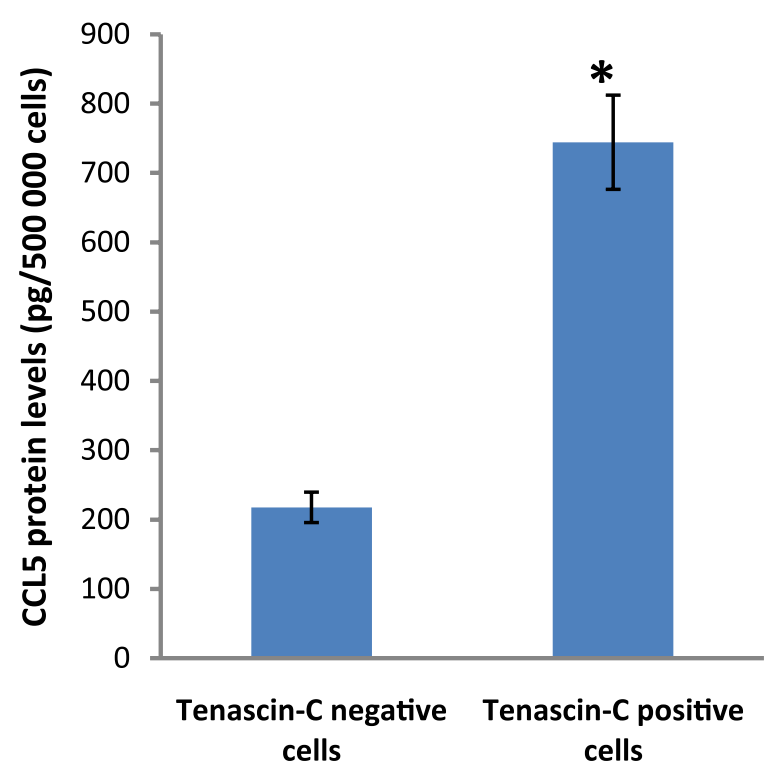

(B)

Fig. 8. (Continued.)

suggest that CCL5 is produced by myofibroblast that developed from tumor activated hASCs.

Jeon et al. [12] showed that ovarian cancer cellderived LPA stimulates the production of TGF $\beta 1$ in hASCs. TGF $\beta 1$ then activates its receptor and stimulates the expression of $\alpha \mathrm{SMA}$ through an autocrine mechanism. Our data confirmed that hASCs indeed express TGF $\beta$ receptor, however, breast cancer cellderived $\operatorname{TGF} \beta 1$ was responsible for the induction of the myofibroblast-like phenotype in a paracrine fashion. It is therefore conceivable that different types of cancer might be able to use different mechanisms to induce the expression of $\alpha$ SMA in hASCs. Jeon et al. [12] further showed that LPA stimulates production of SDF-1 from hASCs through a TGF- $\beta 1$-Smaddependent pathway. Recent studies indicate that stromal cells in the primary tumor are an important source of SDF-1. In myofibroblasts isolated from breast cancer specimens, SDF-1 expression was significantly up-regulated compared to fibroblasts obtained from normal breast tissue [1,21]. Myofibroblasts-derived SDF-1 not only increases carcinoma cell growth directly through the CXCR4 receptor displayed on tumor cells, but also serves to recruit endothelial progenitor cells into tumors, thereby stimulating neoangiogenesis [20]. We demonstrated here that hASCs secrete increased protein levels of SDF-1 when cultured in tu- mor cell conditioned medium, and these data are in line with that reported by Jeon et al. [12].

It has been shown that tenascin-C and scatter factor/hepatocyte growth factor produced by myofibroblasts provide proinvasive signals to cancer cells in vitro [6]. In the present study we found that hASCs previously cultured in TCM or with recombinant TGF $\beta 1$ (in concentrations present in TCM) promote the invasion of MDAMB231 cancer cells more potently than control hASCs without any pre-treatment. Moreover the proinvasive potential of CAF-like CM can be abolished through inhibition of the TGF $\beta$ tyrosine kinases in hASCs. Together with our findings that these activated hASCs express myofibroblast-like immunocytochemical markers, these results further corroborate the assumption that hASCs can differentiate into CAF-like cells under the influence of TGF $\beta 1$ secreted from cancer cells.

Our recently published findings, that co-injection of ASCs with 4T1 promotes tumor growth in a SDF1/ CXCR4 dependent manner, and that ASCs isolated from these tumors show increased expression of $\alpha$-SMA [18], strongly support the in vivo relevance of our current in vitro findings. The essential features of this model system for tumor invasion is that under the influence of tumor cell-derived TGF beta, hASCs can differentiate into myofibroblasts which in turn produce CCL5 and promote tumor cell invasion. We showed that the differentiation of hASCs towards myofibroblasts is dependent on $\mathrm{TGF} \beta 1$ secreted from breast cancer cells since the induction of myofibroblasts was abolished using neutralizing antibodies to TGF $\beta 1$ as well as by pretreatment of the hASCs with SB431542, a TGF $\beta 1$ receptor kinase inhibitor. More importantly, these hASC-derived myofibroblasts exhibit functional properties including the ability to promote tumor cell invasion shown by an in vitro invasion assay. Our data suggest that hASCs are a source of myofibroblasts which play an important role in the tumor microenvironment and that this differentiation can be abolished by inhibition of TGF $\beta 1$.

Together, these findings are of special interest, since hASCs derived from adipose tissue are particularly abundant in breast tissue and might therefore be the most potent early response cells during cancer expansion. These findings identify $\mathrm{TGF} \beta 1$ as a key factor in the differentiation of tissue resident stem cells towards CAF-like cells and suggest that inhibition of the TGF $\beta 1$ pathway in hASCs could offer a possible way to inhibit these cells from promoting the tumor microenvironment. Future studies on tissue-derived stem 
cells within the breast cancer microenvironment under special consideration of TGF $\beta 1$ should be of interest for the development of anti-cancer therapies in the future. The interaction with other mechanisms such as genomic instability [13] and protein oxidation [15] should be considered and evaluated as further mechanisms contributing to tumorigenesis.

\section{Acknowledgements}

This research was supported in part by the Department of Defense Breast Cancer Research Program W81XWH-08-1-0523 01 (to YHS) and by the Alliance of Cardiovascular Researchers (to EA). We thank Feras J. Abdul Khalek and Christoph Beckmann for their technical assistance. The authors are also grateful to Dr. Sendurai Mani for helpful comments on this study.

\section{References}

[1] M. Allinen, R. Beroukhim, L. Cai, C. Brennan, J. LahtiDomenici, H. Huang, D. Porter, M. Hu, L. Chin, A. Richardson, S. Schnitt, W.R. Sellers and K. Polyak, Molecular characterization of the tumor microenvironment in breast cancer, Cancer Cell 6 (2004), 17-32.

[2] X. Bai, J. Ma, Z. Pan, Y.H. Song, S. Freyberg, Y. Yan, D. Vykoukal and E. Alt, Electrophysiological properties of human adipose tissue-derived stem cells, Am. J. Physiol. Cell Physiol. 293 (2007), C1539-C1550.

[3] X. Bai, S. Sadat, S. Gehmert, E. Alt and Y.H. Song, VEGF receptor Flk-1 plays an important role in c-kit expression in adipose tissue derived stem cells, FEBS Lett. 581 (2007), 46814684.

[4] J.A. Burger and T.J. Kipps, CXCR4: a key receptor in the crosstalk between tumor cells and their microenvironment, Blood 107 (2006), 1761-1767.

[5] W.O. De, P. Demetter, M. Mareel and M. Bracke, Stromal myofibroblasts are drivers of invasive cancer growth, Int. J. Cancer 123 (2008), 2229-2238.

[6] O. de Wever, Q.-D. Nguyen, L. van Hoorde, M. Bracke, E. Bruyneel, C. Gespach and M. Mareel, Tenascin-C and $\mathrm{SF} / \mathrm{HGF}$ produced by myofibroblasts in vitro provide convergent pro-invasive signals to human colon cancer cells through RhoA and Rac, FASEB J. 18 (2004), 1016-1018.

[7] N.C. Direkze, K. Hodivala-Dilke, R. Jeffery, T. Hunt, R. Poulsom, D. Oukrif, M.R. Alison and N.A. Wright, Bone marrow contribution to tumor-associated myofibroblasts and fibroblasts, Cancer Res. 64 (2004), 8492-8495.

[8] J.M. Gimble, A.J. Katz and B.A. Bunnell, Adipose-derived stem cells for regenerative medicine, Circ. Res. 100 (2007), 1249-1260.

[9] I. Haviv, K. Polyak, W. Qiu, M. Hu and I. Campbell, Origin of carcinoma associated fibroblasts, Cell Cycle $\mathbf{8}$ (2009), 589_ 595 .
[10] B. Hu, Z. Wu and S.H. Phan, Smad3 mediates transforming growth factor-beta-induced alpha-smooth muscle actin expression, Am. J. Respir. Cell Mol. Biol. 29 (2003), 397-404.

[11] G. Ishii, T. Sangai, T. Oda, Y. Aoyagi, T. Hasebe, N. Kanomata, Y. Endoh, C. Okumura, Y. Okuhara, J. Magae, M. Emura, T. Ochiya and A. Ochiai, Bone-marrow-derived myofibroblasts contribute to the cancer-induced stromal reaction, Biochem. Biophys. Res. Commun. 309 (2003), 232-240.

[12] E.S. Jeon, H.J. Moon, M.J. Lee, H.Y. Song, Y.M. Kim, M. Cho, D.S. Suh, M.S. Yoon, C.L. Chang, J.S. Jung and J.H. Kim, Cancer-derived lysophosphatidic acid stimulates differentiation of human mesenchymal stem cells to myofibroblast-like cells, Stem Cells 26 (2008), 789-797.

[13] A. Kuijper, A.M. Snijders, E.M. Berns, V. KuenenBoumeester, E. van der Wall, D.G. Albertson and P.J. van Diest, Genomic profiling by array comparative genomic hybridization reveals novel DNA copy number changes in breast phyllodes tumours, Cell. Oncol. 31 (2009), 31-39.

[14] L.A. Kunz-Schughart and R. Knuechel, Tumor-associated fibroblasts (part I): Active stromal participants in tumor development and progression?, Histol. Histopathol. 17 (2002), 599621.

[15] F. Mannello, G.A. Tonti and V. Medda, Protein oxidation in breast microenvironment: Nipple aspirate fluid collected from breast cancer women contains increased protein carbonyl concentration, Cell. Oncol. 31 (2009), 383-392.

[16] J. Massague, TGFbeta in cancer, Cell 134 (2008), 215-230.

[17] P.J. Mishra, P.J. Mishra, R. Humeniuk, D.J. Medina, G. Alexe, J.P. Mesirov, S. Ganesan, J.W. Glod and D. Banerjee, Carcinoma-associated fibroblast-like differentiation of human mesenchymal stem cells, Cancer Res. 68 (2008), 4331-4339.

[18] F.L. Muehlberg, Y.H. Song, A. Krohn, S.P. Pinilla, L.H. Droll, X. Leng, M. Seidensticker, J. Ricke, A.M. Altman, E. Devarajan, W. Liu, R.B. Arlinghaus and E.U. Alt, Tissue-resident stem cells promote breast cancer growth and metastasis, Carcinogenesis 30 (2009), 589-597.

[19] A. Muller, B. Homey, H. Soto, N. Ge, D. Catron, M.E. Buchanan, T. McClanahan, E. Murphy, W. Yuan, S.N. Wagner, J.L. Barrera, A. Mohar, E. Verastegui and A. Zlotnik, Involvement of chemokine receptors in breast cancer metastasis, Nature 410 (2001), 50-56.

[20] A. Orimo and R.A. Weinberg, Stromal fibroblasts in cancer: a novel tumor-promoting cell type, Cell Cycle 5 (2006), 15971601.

[21] A. Orimo, P.B. Gupta, D.C. Sgroi, F. Renzana-Seisdedos, T. Delaunay, R. Naeem, V.J. Carey, A.L. Richardson and R.A. Weinberg, Stromal fibroblasts present in invasive human breast carcinomas promote tumor growth and angiogenesis through elevated SDF-1/CXCL12 secretion, Cell 121 (2005), 335-348.

[22] S. Pinilla, E. Alt, F.J.A. Khalek, C. Jotzu, F. Muehlberg, C. Beckmann and Y.H. Song, Tissue resident stem cells produce CCL5 under the influence of cancer cells and thereby promote breast cancer cell invasion, Cancer Lett. 284(1) (2009), 80-85.

[23] L. Ronnov-Jessen and O.W. Petersen, Induction of alphasmooth muscle actin by transforming growth factor-beta 1 in quiescent human breast gland fibroblasts. Implications for myofibroblast generation in breast neoplasia, Lab. Invest. 68 (1993), 696-707.

[24] A.P. Sappino, O. Skalli, B. Jackson, W. Schurch and G. Gabbiani, Smooth-muscle differentiation in stromal cells of ma- 
lignant and non-malignant breast tissues, Int. J. Cancer $\mathbf{4 1}$ (1988), 707-712.

[25] E.L. Spaeth, J.L. Dembinski, A.K. Sasser, K. Watson, A. Klopp, B. Hall, M. Andreeff and F. Marini, Mesenchymal stem cell transition to tumor-associated fibroblasts contributes to fibrovascular network expansion and tumor progression, PLoS One 4 (2009), e4992.

[26] B.A. Teicher, Malignant cells, directors of the malignant process: role of transforming growth factor-beta, Cancer Metastasis Rev. 20 (2001), 133-143.

[27] T. Tsujino, I. Seshimo, H. Yamamoto, C.Y. Ngan, K. Ezumi, I. Takemasa, M. Ikeda, M. Sekimoto, N. Matsuura and M. Monden, Stromal myofibroblasts predict disease recurrence for colorectal cancer, Clin. Cancer Res. 13 (2007), 2082-2090.

[28] J.A. Tuxhorn, G.E. Ayala and D.R. Rowley, Reactive stroma in prostate cancer progression, J. Urol. 166 (2001), 2472-2483.
[29] D. Wang, J.S. Park, J.S. Chu, A. Krakowski, K. Luo, D.J. Chen and S. Li, Proteomic profiling of bone marrow mesenchymal stem cells upon transforming growth factor beta1 stimulation, J. Biol. Chem. 279 (2004), 43725-43734.

[30] M.M. Webber, N. Trakul, P.S. Thraves, D. Bello-DeOcampo, W.W. Chu, P.D. Storto, T.K. Huard, J.S. Rhim and D.E. Williams, A human prostatic stromal myofibroblast cell line WPMY-1: a model for stromal-epithelial interactions in prostatic neoplasia, Carcinogenesis 20 (1999), 1185-1192.

[31] C. Yazhou, S. Wenlv, Z. Weidong and W. Licun, Clinicopathological significance of stromal myofibroblasts in invasive ductal carcinoma of the breast, Tumour Biol. 25 (2004), 290-295.

[32] P.A. Zuk, M. Zhu, H. Mizuno, J. Huang, J.W. Futrell, A.J. Katz, P. Benhaim, H.P. Lorenz and M.H. Hedrick, Multilineage cells from human adipose tissue: implications for cell-based therapies, Tissue Eng. 7 (2001), 211-228. 


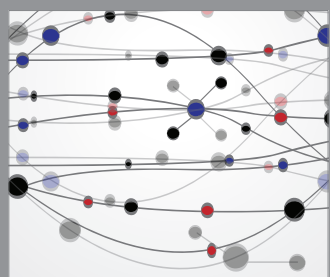

The Scientific World Journal
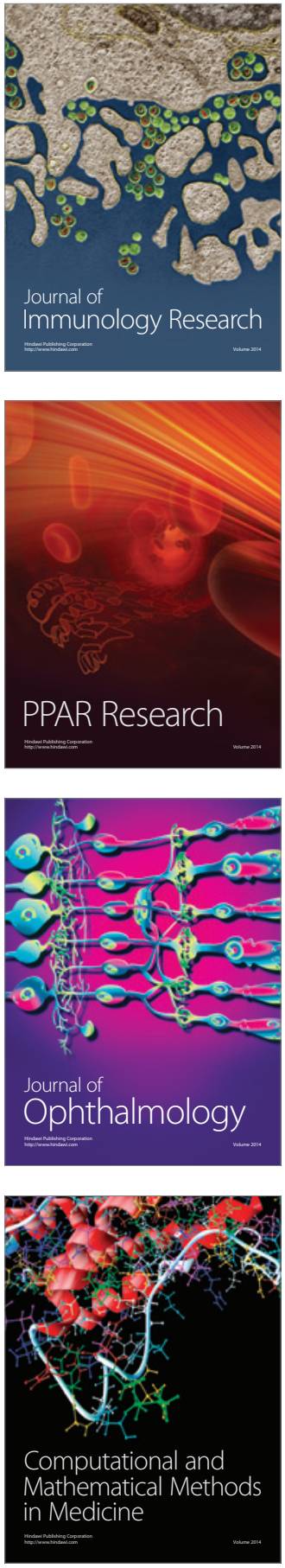

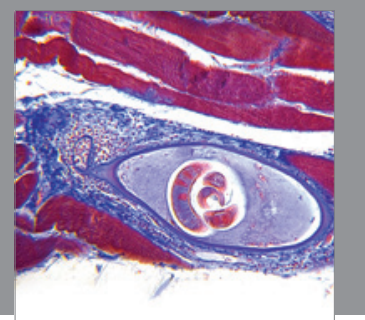

Gastroenterology

Research and Practice
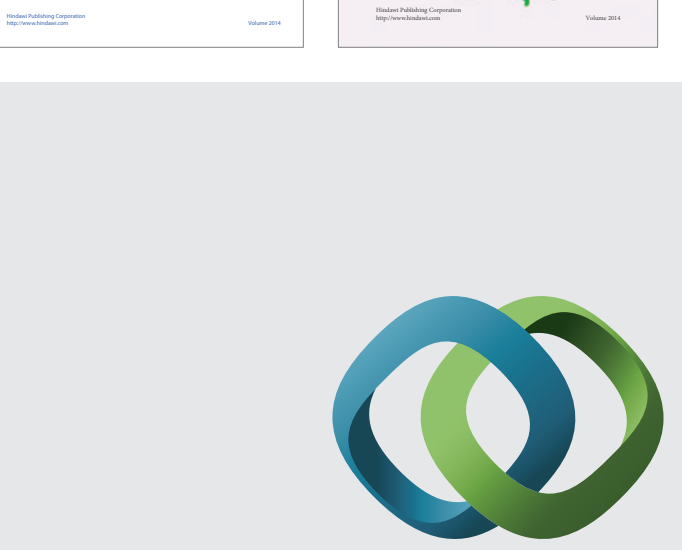

\section{Hindawi}

Submit your manuscripts at

http://www.hindawi.com
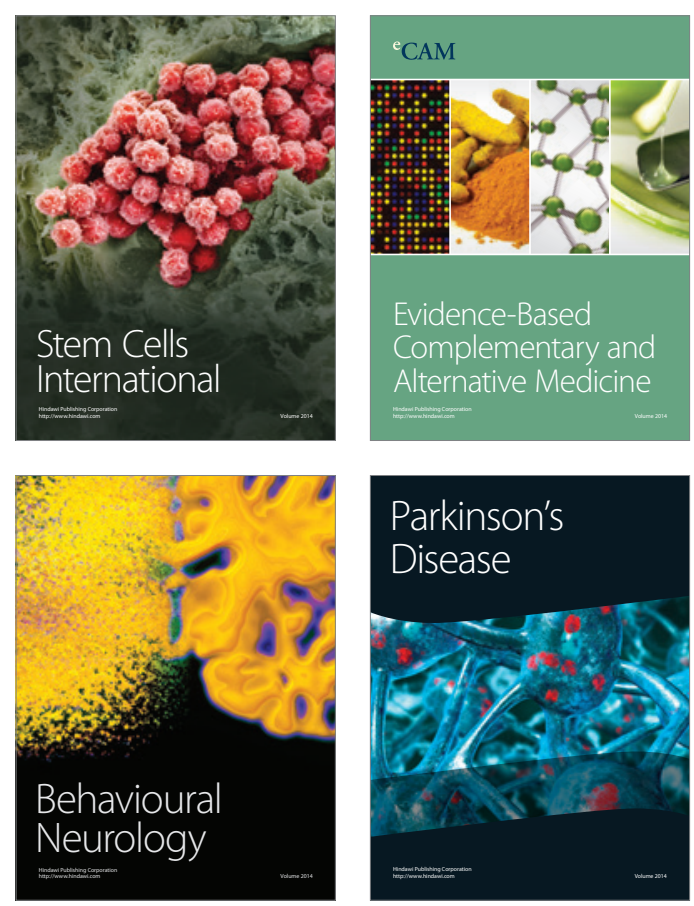

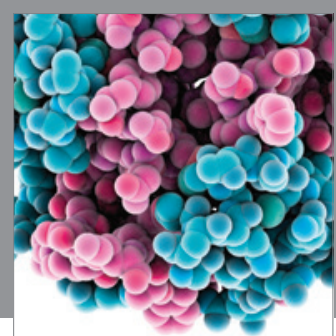

Journal of
Diabetes Research

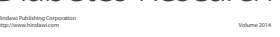

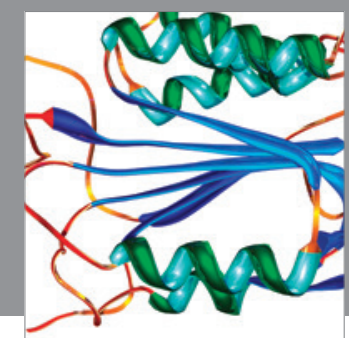

Disease Markers
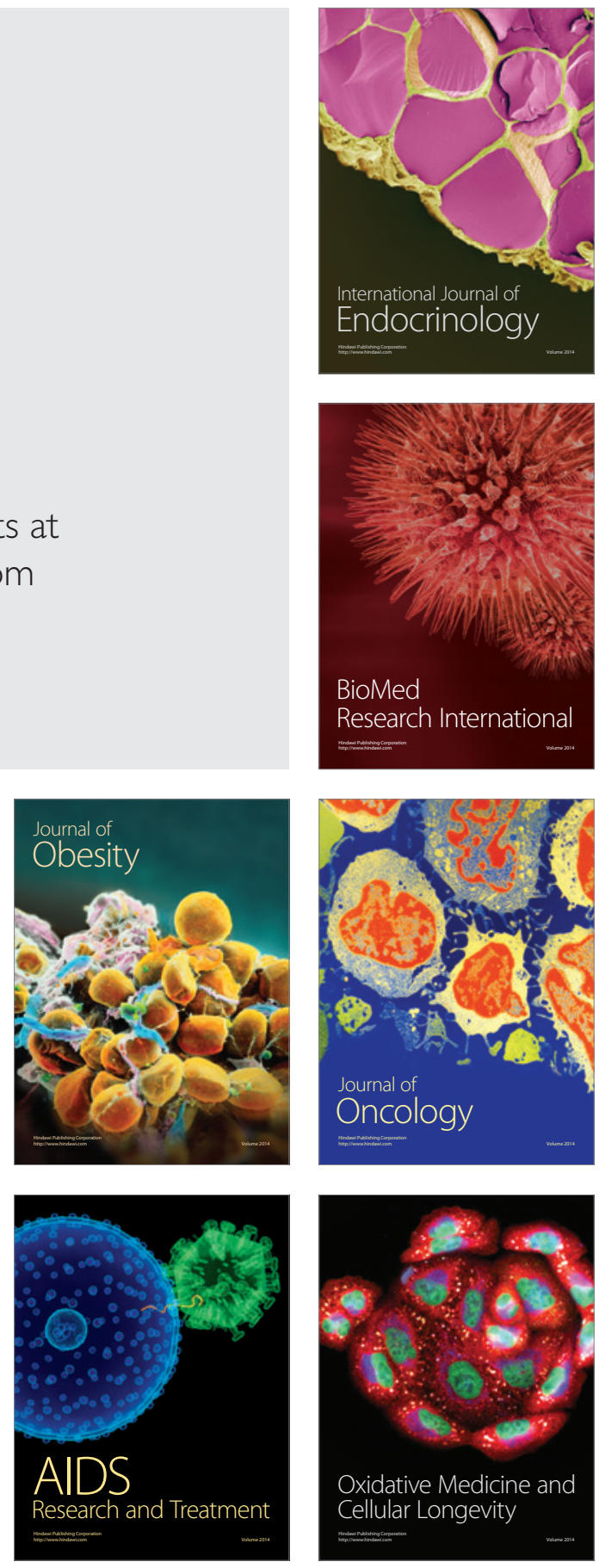